\title{
Reference Tables for the Platinel II Thermocouple
}

\author{
L. O. Olsen and P. D. Freeze
}

(May 28, 1964)

\begin{abstract}
A new thermocouple, Platinel II, was developed by Engelhard Industries, Inc., for sustained operation in oxidizing gases at temperatures higher than those possible with Type $\mathrm{K}$ thermocouples, yet having a temperature thermal emf relation comparable to them. The need of reference tables for this thermocouple was made evident by the growing acceptance and increased usage of it.

Twenty-seven thermocouples made of 20-, 30-, and 40-mil diameter elements drawn from three separate melts of the positive and negative alloys were calibrated. Three equations for three temperature ranges were found to fit the averaged data of all thermocouples with a maximum deviation of only 9 microvolts. The reference tables presented were computed from these three equations. They give emfs for each degree Celsius from -100 to $1371^{\circ} \mathrm{C}$ and for each degree Fahrenheit from -150 to $2500{ }^{\circ} \mathrm{F}$. Usually these tables, when used in conjunction with any typical undamaged Platinel II thermocouple, will provide temperatures which are not in error by more than 3,5 , and $10{ }^{\circ} \mathrm{F}$ at 500,1000 , and $2500{ }^{\circ} \mathrm{F}$, respectively. Other tables are of temperatures in both degrees $\mathrm{C}$ and degrees $\mathrm{F}$ with emf in millivolts as the argument.

Tables of temperature versus emf of the two elements of Platinel II versus Pt 27 and of copper versus the two elements are also presented. A comparison of the thermal emf of Platinel II with that of Chromel-Alumel is shown. The two thermocouples develop identical emfs at 32,1300 , and $2225^{\circ} \mathrm{F}$. Between 1000 and $2500^{\circ} \mathrm{F}$ the maximum indicated difference is only $18{ }^{\circ} \mathrm{F}$ when the Chromel-Alumel reference table is used.
\end{abstract}

\section{Introduction}

Along with the advances in the technologies of combustion and metallurgy have come substantial increases in the temperature of gaseous products emanating from heat engines. The continuing effort to increase thrust and efficiencies of propulsion engines presages even higher temperatures of exhaust gas in the future. As a result of these higher temperatures a need has arisen for thermocouples capable of sustained operation in hot oxidizing gases. In the past and for most applications at present the base-metal type $K$ thermocouples are adequate for the measurement and control of temperatures of gaseous mixtures. However, as temperatures increase, the thermoelectric stability and life expectancy of such thermocouples will not be satisfactory. For instance, they will not last for the usual 1000 hours between jet engine overhauls. Replacement of thermocouples in jet engines is a very costly procedure not only because of thermocouple expense but also because of the very large labor cost. Therefore, any thermocouple system which needs neither repairs nor replacement during the period between major overhauls will result in substantial savings. The same advantages will accrue to other industrial equipment and processes that involve temperatures that are too high for long-time continued use of the conventional thermocouples.
For these reasons Accinno and Schneider [1] ${ }^{1}$ and [2] developed Platinel. ${ }^{2}$ Two different combinations have been produced and are named Platinel I and Platinel II. The negative element in each of the thermocouples consists of 65 percent gold and 35 percent palladium (Platinel 1503). The positive element in Platinel $I$ is an alloy containing 83 percent palladium, 14 percent platinum and 3 percent gold (Platinel 1786) and that used in Platinel II contains 55 percent palladium, 31 percent platinum and 14 percent gold (Platinel 1813). Zysk [3] reports that because of its superior mechanical fatigue properties Platinel II is the preferred type.

Following the development of the Platinel thermocouple, a considerable amount of work of evaluating its properties was performed at both Engelhard Industries, Inc. [4] and the National Bureau of Standards [5]. The results of these works indicated the Platinel II thermocouple to be considerably more resistant to oxidation than the type $\mathrm{K}$ thermocouples over the entire usable range of temperatures. In addition, the thermoelectric stability was found to be quite good. The changes in thermal emf remained within a $\pm 3 / 4$ percent tolerance for 1000 hr of exposure to air at $2200^{\circ} \mathrm{F}$.

\footnotetext{
1 Figures in brackets indicate the literature references on page 271

2 Registered Trademark of Engelhard Industries, Inc. Patent U.S. 3,066,177. November 27, 1962.
} 
On the basis of these promising results it was decided to establish reference tables for this thermocouple so that it can be used more widely and conveniently. It was further decided to fit empirical equations to the calibration data, if possible, in order to avoid the necessity of storing the complete table when making computer calculations.

A description of reference tables for thermocouples and instructions for their use in conjunction with deviation curves are given by Shenker et al. [6]: "The temperature-electromotive-force relationship for a thermocouple in general cannot be expressed by a simple equation. It is convenient, therefore, to have empirical tables giving the temperatureelectromotive-force relationship for the various types of commercially available thermocouples. For any thermocouple type, a table is based on calibrations of representative thermocouples at sufficient points to yield a temperature-electromotiveforce plot characteristic of the material. These tables, therefore, do not represent the temperatureelectromotive-force relationship for a particular thermocouple but rather a mean of a number of thermocouples of that type. The reference tables so derived provide a basis for drawing deviation curves for comparing individual thermocouples with others of their type or with instruments calibrated to read temperature directly. By using the reference tables in conjunction with a deviation curve, greater precision may be obtained by using a given number of calibration points than from the use of the calibration data alone. The deviation curve is constructed by plotting the differences between the calibration data of an individual instrument and the reference table. The points so plotted may then be connected by a continuous curve which may be used for interpolating between calibration points. For example, it is desired to determine the temperature of a furnace from the measured electromotive force of a calibrated thermocouple. The electromotive force developed by the thermocouple, however, does not correspond to that of any of the calibration points. By plotting a difference curve from the calibration data, one may interpolate between the calibration points to find the correction to be added algebraically to the measured electromotive force to yield the reference table value. The reference table may now be referred to and the furnace temperature corresponding to the corrected thermocouple electromotive force determined."

\section{Thermocouples}

In order for the calibrations obtained in this work to be representative of Platinel II, three lots of each of the positive and negative elements from separate melts were purchased from Englehard Industries, Inc., the proprietors of this thermocouple. The three lots $\mathrm{A}, \mathrm{B}$, and $\mathrm{C}$ were selected from wires drawn from bars designated by numbers assigned by the maker as follows:

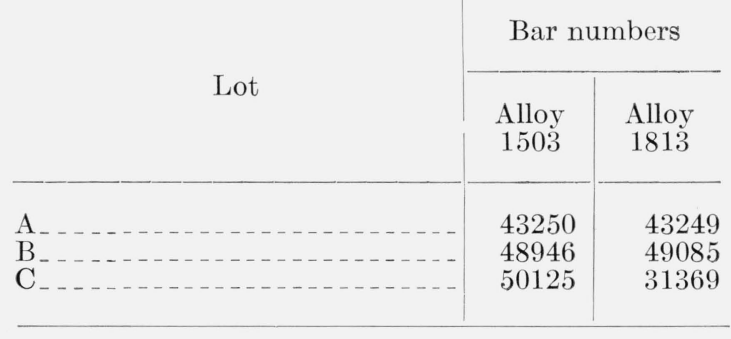

Wires of each of the bars were drawn to 20-, 30-, and 40-mil diameters. Three thermocouples of each wire size and lot were made; thus, 27 thermocouples were available for calibration. They were identified by numbers such as $2-\mathrm{B}-30$, where the first number refers to the number of the thermocouple, the letter to lot, and the last number to wire diameter in mils.

All elements were 48 in. long and prior to calibration were annealed at a temperature of $2400{ }^{\circ} \mathrm{F}$ for a period of $90 \mathrm{~min}$. This was accomplished through electric heating with alternating current in clean draft-free air. The reasons for this lengthy anneal at high temperature are discussed in a later section.

\section{Apparatus and Experimental Procedure}

All thermocouples with the exception of $3-\mathrm{A}-40$ were calibrated as described above. Thermocouple $3-\mathrm{A}-40$ was reserved for calibration at temperatures below $32{ }^{\circ} \mathrm{F}$ and comparison with other selected samples at these low temperatures. It was calibrated at six temperatures from $-148{ }^{\circ} \mathrm{F}$ to $77^{\circ} \mathrm{F}$. These measurements were made in a stirred bath of a cryogenic liquid by members of the Temperature Physics Section. The uncertainty of the measurements below $32{ }^{\circ} \mathrm{F}$ was reported to be $\pm 0.2{ }^{\circ} \mathrm{F}$. Using thermocouple $3-\mathbf{A}-40$ as a standard, six other selected thermocouples were compared with it over the same temperature range and with approximately the same uncertainty. Thus, over the range of temperatures from $-148{ }^{\circ} \mathrm{F}$ to $77{ }^{\circ} \mathrm{F}$ the reference tables are the results of the measurements on the seven following thermocouples: $3-\mathrm{A}-40,1-\mathrm{B}-30$, $2-\mathrm{B}-30, \quad 3-\mathrm{B}-30, \quad 1-\mathrm{C}-20,1-\mathrm{C}-30$, and $1-\mathrm{C}-40$. From $100{ }^{\circ} \mathrm{F}$ to $2500{ }^{\circ} \mathrm{F}$ the reference tables are determined from the results of calibrations of 26 thermocouples.

The calibrations from $100{ }^{\circ} \mathrm{F}$ to $2500{ }^{\circ} \mathrm{F}$ were conducted in a Pereny horizontal tube furnace. The tubular heating element was of silicon carbide, $36 \mathrm{in}$. long with an inside diameter of $3.5 \mathrm{in}$. Temperature regulation and control were accomplished with a 36 tap transformer, a saturable core reactor, and a Wheelco controller.

To prevent contamination of the thermocouples from the silicon carbide heating element, a high temperature porcelain, closed end, protection tube (36 in. long with an inside diameter of 3 in.) was inserted into the heating element. 
Further protection was provided by another closed end tube of Degussit $\mathrm{Al}$ 23, a high-purity impervious alumina. It was supported only near the relatively cool open end and its axis coincided with that of the heating element. This tube had an inside diameter of $12 \mathrm{~mm}$ and a length of $24 \mathrm{in}$. Thermal gradients along the axis of this protection tube were found to be quite small near the center of the furnace (i.e. 18 in. from the open end of the furnace tube). A typical temperature traverse along the axis from the and to the center of the tube is shown in figure 1 for a furnace temperature of about $2400{ }^{\circ} \mathrm{F}$ where there is a drop in temperature of only $10{ }^{\circ} \mathrm{F}$ from the center of the tube to a distance $4 \mathrm{in}$. from the center.

Three Platinel II thermocouples along with a calibrated 20-mil platinum versus platinum 10 percent rhodium thermocouple used as the standard of comparison were threaded through two pieces of 24-in.long Degussit Al 23, four-hole tubing. All eight wires were pressed into intimate electrical and thermal contact by flattening a short piece of small platinum tubing over them. This common junction was placed about 1 in. beyond the center of the furnace tube thereby locating the junction and $2 \mathrm{in}$. of the thermocouples in virtually a gradient free zone as shown in figure 1.

Measurements of the thermal emf of the standard and test thermocouples were made by simultaneous reading of two Leeds \& Northrup Type K-3 potentiometers. Measurements of the thermal emf of all test thermocouple elements versus platinum were also made.

Observations were made in increments of about $50{ }^{\circ} \mathrm{F}$ from $100{ }^{\circ} \mathrm{F}$ to $2300{ }^{\circ} \mathrm{F}$. This was followed by another series of observations made in descending order of $50^{\circ} \mathrm{F}$ increments down to $100{ }^{\circ} \mathrm{F}$. Measurements were then made from $2300{ }^{\circ} \mathrm{F}$ to $2500{ }^{\circ} \mathrm{F}$ and back down to $2300{ }^{\circ} \mathrm{F}$, again at $50{ }^{\circ} \mathrm{F}$ intervals. These measurements were made last because of the decreased stability of the thermocouples at these higher temperatures. The maximum deviation from integral multiples of $50{ }^{\circ} \mathrm{F}$ was $5^{\circ} \mathrm{F}$ while the vast majority did not exceed $2{ }^{\circ} \mathrm{F}$.

The platinum versus platinum 10 percent rhodium thermocouples used as standards of comparison were calibrated before and after the calibration of each group of three Platinel II thermocouples. These calibrations were made with a platinum versus platinum 10 percent rhodium thermocouple which had a primary calibration and was used exclusively for this work. The thermal emfs of the individual elements of Platinel II versus platinum were determined between 0 and $1450{ }^{\circ} \mathrm{C}$ at intervals of about $100{ }^{\circ} \mathrm{C}$. Thus, these can be referred to $\mathrm{Pt} 27$, the platinum reference standard, which is maintained at the National Bureau of Standards. The uncertainties of interpolated values are $\pm 0.5{ }^{\circ} \mathrm{C}$ up to $1100{ }^{\circ} \mathrm{C}$ and $\pm 2{ }^{\circ} \mathrm{C}$ at $1450{ }^{\circ} \mathrm{C}[7]$. On the Fahrenheit scale of temperature these correspond to about $\pm 0.8^{\circ} \mathrm{F}$ up to $2000{ }^{\circ} \mathrm{F}$ and $\pm 3.0^{\circ} \mathrm{F}$ at $2500{ }^{\circ} \mathrm{F}$. The maximum change in calibration of any of the standard thermocouples was only about $0.6^{\circ} \mathrm{F}$ and

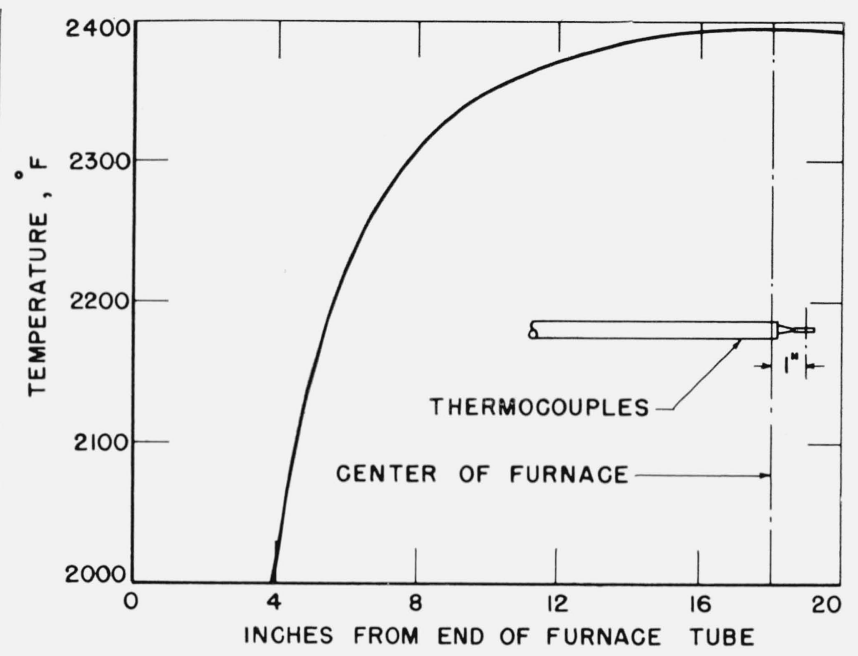

Figure 1. Typical temperature gradient in furnace tube.

occurred at about $900{ }^{\circ} \mathrm{F}$. Most of this change developed during its first use. The inaccuracies of the two potentiometers contribute slightly to the uncertainty in the values of the temperature of the test thermocouples. The maximum error in the measurement of the emf of the platinum versus platinum 10 percent rhodium thermocouple is \pm 0.2 to $\pm 1.8 \mu \mathrm{V}$. The corresponding errors in the measurements of the Platinel II thermocouple are \pm 0.2 to $\pm 7.5 \mu \mathrm{V}$. These errors combine to increase the uncertainty about $\pm 1.1^{\circ} \mathrm{F}$ at $2500{ }^{\circ} \mathrm{F}$. Thus, the maximum uncertainty is about $\pm 4^{\circ} \mathrm{F}$ at $2500^{\circ} \mathrm{F}$.

\section{Computations}

In the temperature range from $-148^{\circ} \mathrm{F}$ to $77^{\circ} \mathrm{F}$ the reference tables are based on the results of seven previously designated thermocouples. One observation on each thermocouple was made at each of six different temperatures within this range of temperatures. The averages of the observations (temperature and emf) on all seven thermocouples at each of these six temperatures were then calculated. From $100{ }^{\circ} \mathrm{F}$ to $2500{ }^{\circ} \mathrm{F}$, at $50{ }^{\circ} \mathrm{F}$ intervals, the observations on 26 thermocouples in both ascending and descending order of temperature were averaged. Thus, for this range of temperatures, each averaged observation is the result of 52 separate measurements. These data consisting of 55 temperatures and their corresponding emfs are shown in table 1. In the absence of a known functional form for the relation of temperature and emf, a set of three polynomial ares were used as an approximation to the function. There is some arbitrariness in the selection of the number of intervals and also the width of these intervals. After several trials it was found that equations for three ranges of temperature gave a good fit to the data. 
TABLE 1. Fifty-five averages of observations on Platinel II thermocouples

Electromotive force in absolute millivolts. Temperature in degrees $\mathrm{F}^{*}$. Reference junctions at $32{ }^{\circ} \mathrm{F}$.

\begin{tabular}{|c|c|c|c|}
\hline Temperature & Millivolts & Temperature & Millivolts \\
\hline $\begin{array}{r}{ }^{\circ} F \\
-148.0 \\
-103.0 \\
-58.0 \\
-13.0\end{array}$ & $\begin{array}{l}-2.587 \\
-2.008 \\
-1.384 \\
-0.718\end{array}$ & $\begin{array}{c}{ }^{\circ} F \\
1198.4 \\
1248.6 \\
1298.4 \\
1349.1\end{array}$ & $\begin{array}{l}26.815 \\
28.053 \\
29.274 \\
30.507\end{array}$ \\
\hline $\begin{array}{r}32.0 \\
77.0 \\
101.7 \\
149.0\end{array}$ & $\begin{array}{l}0.000 \\
0.768 \\
1.209 \\
2.076\end{array}$ & $\begin{array}{l}1398.1 \\
1448.5 \\
1497.6 \\
1547.8\end{array}$ & $\begin{array}{l}31.688 \\
32.887 \\
34.048 \\
35.217\end{array}$ \\
\hline $\begin{array}{l}200.0 \\
248.8 \\
299.1 \\
349.1\end{array}$ & $\begin{array}{l}\text { 3. } 054 \\
4.038 \\
5.089 \\
6.169\end{array}$ & $\begin{array}{l}1599.2 \\
1649.8 \\
1698.4 \\
1747.0\end{array}$ & $\begin{array}{l}36.396 \\
37.547 \\
38.630 \\
39.712\end{array}$ \\
\hline $\begin{array}{l}400.2 \\
449.9 \\
498.4 \\
549.3\end{array}$ & $\begin{array}{r}7.304 \\
8.432 \\
9.547 \\
10.742\end{array}$ & $\begin{array}{l}1797.5 \\
1848.5 \\
1898.6 \\
1949.3\end{array}$ & $\begin{array}{l}40.816 \\
41.916 \\
42.986 \\
44.053\end{array}$ \\
\hline $\begin{array}{l}599.5 \\
649.6 \\
698.5 \\
749.1\end{array}$ & $\begin{array}{l}11.939 \\
13.154 \\
14.352 \\
15.600\end{array}$ & $\begin{array}{l}1998.2 \\
2049.3 \\
2099.1 \\
2148.7\end{array}$ & $\begin{array}{l}45.070 \\
46.113 \\
47.116 \\
48.098\end{array}$ \\
\hline $\begin{array}{l}799.4 \\
849.5 \\
900.2 \\
948.9\end{array}$ & $\begin{array}{l}16.840 \\
18.091 \\
19.360 \\
20.580\end{array}$ & $\begin{array}{l}2199.2 \\
2249.6 \\
2300.0 \\
2350.3\end{array}$ & $\begin{array}{l}49.082 \\
50.043 \\
50.984 \\
51.906\end{array}$ \\
\hline $\begin{array}{r}999.0 \\
1048.6 \\
1098.5 \\
1150.0\end{array}$ & $\begin{array}{l}21.832 \\
23.075 \\
24.326 \\
25.614\end{array}$ & $\begin{array}{l}2399.1 \\
2450.2 \\
2499.7\end{array}$ & $\begin{array}{l}52.791 \\
53.701 \\
54.568\end{array}$ \\
\hline
\end{tabular}

*Based on the International Practical Temperature Scale of 1948.

An equation of the fourth degree with coefficients computed to give a least square fit to the data from $-148^{\circ} \mathrm{F}$ to $948.9^{\circ} \mathrm{F}$ was found to be

Millivolts $=1.6522713 \times 10^{-2} t+1.1041292 \times 10^{-5} t^{2}$ $-6.0798812 \times 10^{-9} t^{3}+1.1800871 \times 10^{-12} t^{4}$

where $t=$ (temperature in degrees Fahrenheit) $-32^{\circ}$. This equation is used from $-150{ }^{\circ} \mathrm{F}$ to $873{ }^{\circ} \mathrm{F}$ and shows a maximum deviation from the data of $9 \mu \mathrm{V}$.
From $873{ }^{\circ} \mathrm{F}$ to $1178{ }^{\circ} \mathrm{F}$ the reference tables are computed from a linear equation derived from the data ranging from $900.2^{\circ} \mathrm{F}$ to $1150.0^{\circ} \mathrm{F}$.

$$
\text { Millivolts }=-2.3779626+2.5037757 \times 10^{-2} t^{3} .
$$

In this range the maximum deviation of the data from the reference table is $2 \mu \mathrm{V}$. From $1178{ }^{\circ} \mathrm{F}$ to $2500{ }^{\circ} \mathrm{F}$ the reference table is developed by another equation of the fourth degree with coefficients computed from the data from $1048.6{ }^{\circ} \mathrm{F}$ to $2499.7{ }^{\circ} \mathrm{F}$. The maximum deviation is again $9 \mu \mathrm{V}$.

$$
\begin{gathered}
\text { Millivolts }=-3.5875425+2.6136249 \times 10^{-2} t \\
+1.1471194 \times 10^{-6} t^{2}-1.1611900 \times 10^{-9} t^{3} \\
+1.1112684 \times 10^{-13} t^{4}
\end{gathered}
$$

The maximum deviation of $9 \mu \mathrm{V}$ was considered satisfactorily small; hence, using the three equations the computer was used to calculate emfs for each degree Celsius from -100 to 1371, and for each degree Fahrenheit from -150 to 2500 . These values are shown in tables $2 \mathrm{~A}$ and $4 \mathrm{~A}$ in the appendix. Tables $1 \mathrm{~A}$ and $3 \mathrm{~A}$, which are emf versus degrees $\mathrm{C}$ and emf versus degrees $\mathrm{F}$, were obtained from interpolation at $0.1 \mathrm{mV}$ intervals and the temperatures are reported to the nearest tenth of a degree.

\section{Results and Discussion}

The principal results of this work are the reference tables, 1A, 2A, 3A, and 4A, which show excellent agreement with the earlier work of Zysk [3]. The maximum difference between these tables and his preliminary tables is only $80 \mu \mathrm{V}$. Other information arising from the experiments is of considerable interest and is also presented.

The maximum deviation of the reference tables from the averaged experimental values in table 1 as computed from the equations is $9 \mu \mathrm{V}$. A plot of all such deviations is presented in figure 2 . While the

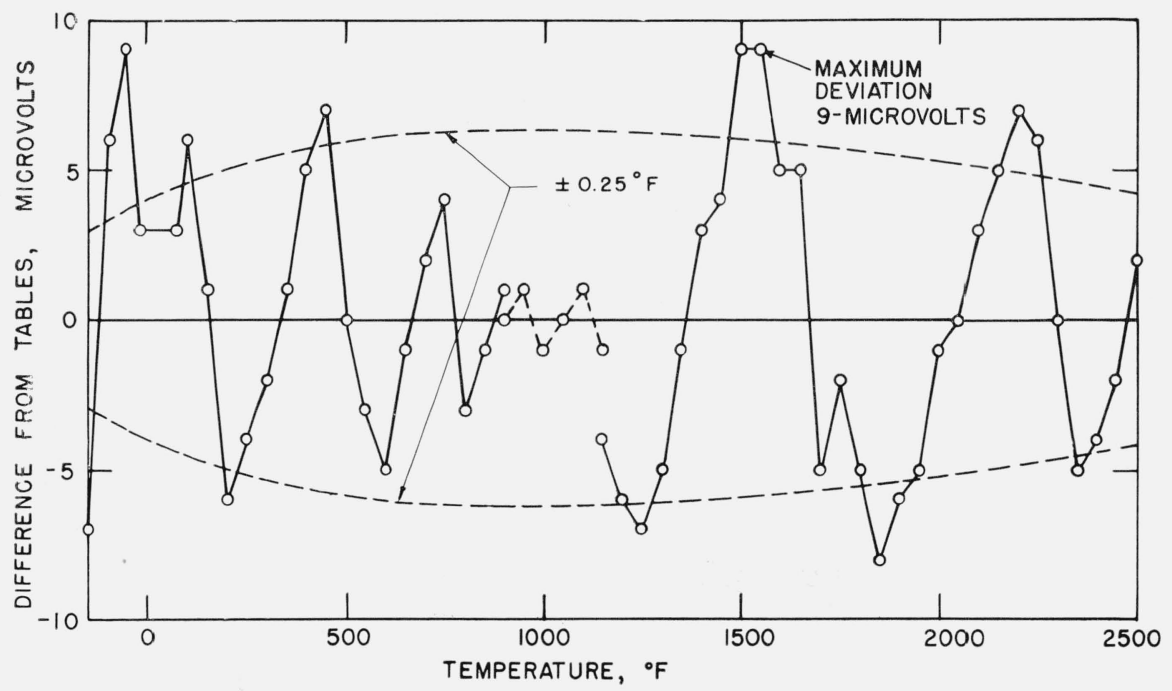

Figure 2. Differences between averaged experimental and reference table values of thermal emf. 
deviations show a definite cyclic pattern, the same pattern was also present in deviations from fifth- and sixth-degree polynomials fit to the same sets of data. The situation is analogous to the mathematical problem of approximating a segment of, say, the exponential or sine curve by a polynomial. It cannot fit the function exactly, but achieves its best fit by undulating about the curve as closely as possible [11]. The reductions in the maximum deviations, going from fourth- to fifth- or sixth-degree polynomials, were small, and the deviations are small as compared to the deviation of individual thermocouples from the reference tables and to the change in emf through exposure to elevated temperatures. In view of these facts, the fourth-degree equations in conjunction with the linear equation were considered to give an adequate representation of the function for the purpose at hand. The deviations are in fact so small they can be ignored and the values in the reference tables as calculated from the three equations need not be adjusted. Thus, a temperature-emf relation with no discontinuities is provided. Such a relation is considered desirable by Benedict and Ashby [8] for computer application. They have "improved" existing tables for base-metal thermocouples with selected values at 50-deg intervals and a second-degree Lagrange interpolation for all values between selected values. If computer programming would be simplified by such interpolation, these data should be amenable to such treatment. However, it seems likely that the three equations will be more convenient in computer programming.

Figure 3 is presented to show the deviations of individual measurements from the values in the reference tables. They are derived from the measurements of all 26 thermocouples in both ascending and descending order. Thus, at each of the six selected temperatures shown, there are 52 individual deviations. The maximum deviation is $116 \mu \mathrm{V}$ at $2500{ }^{\circ} \mathrm{F}$, which corresponds to about $6.7{ }^{\circ} \mathrm{F}$ or 0.26 percent. At $500{ }^{\circ} \mathrm{F}$ the maximum deviation is 50 $\mu \mathrm{V}$, which corresponds to $2.2^{\circ} \mathrm{F}$ or 0.43 percent. These values are well within the usual tolerance of $3 / 4$ percent allowed for base-metal thermocouples. As a matter of fact, nearly all of the thermocouples are within the $3 / 8$ percent tolerance for selected wires. On the basis of these experiments with 26 thermocouples from three different lots of wire it seems safe to say that the temperature of any Platinel II thermocouple, as determined from the reference tables, will

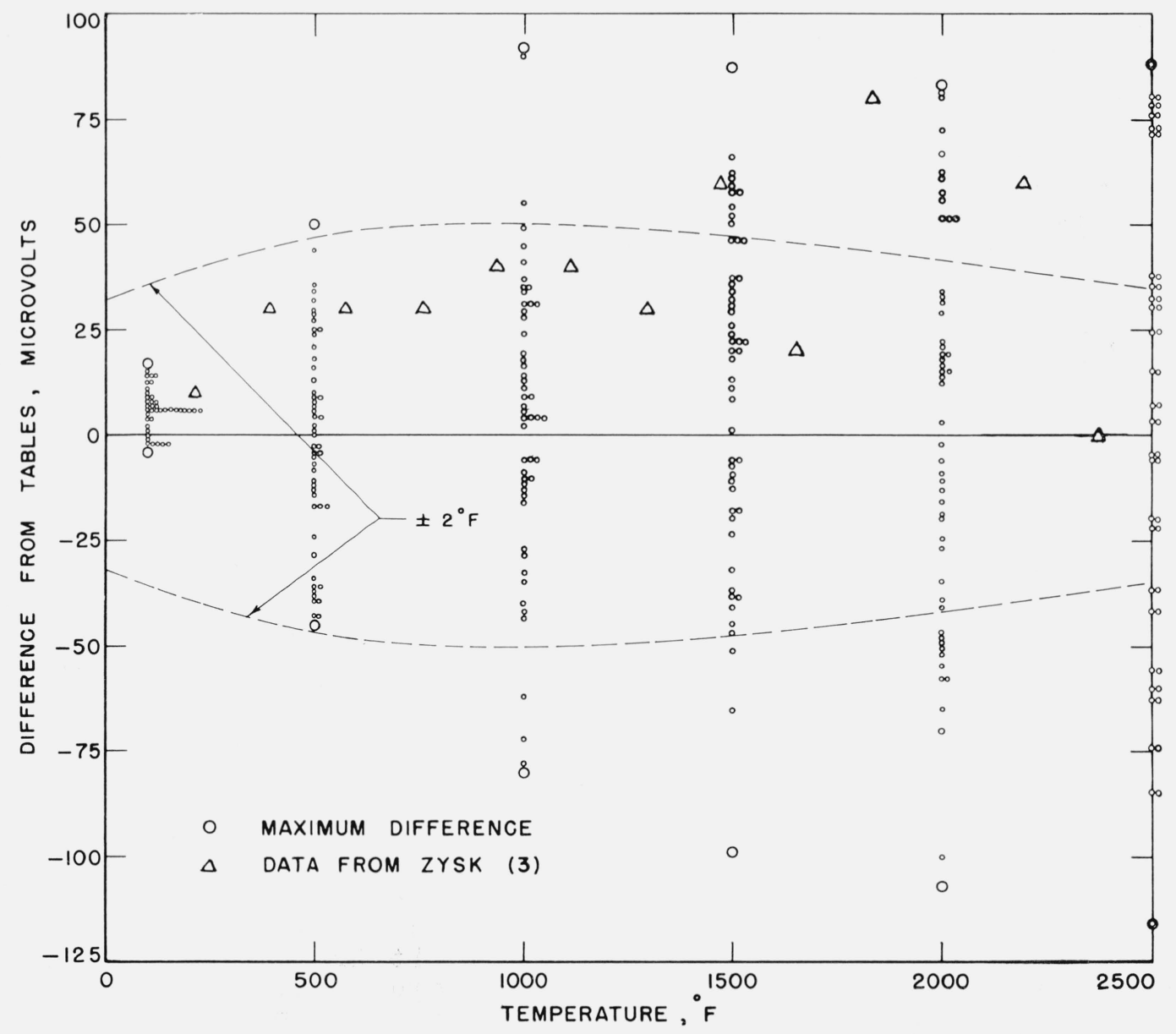

Figure 3. Differences between individual experimental and reference table values of thermal emf. 
be within 0.5 percent of the true temperature. Thus, for most work, a calibration of the thermocouple will not be necessary. It is interesting to note that Zysk's calibration also falls within these limits. The triangular symbols shown on figure 3 are the data from [3].

It was not convenient to indicate individual thermocouples on figure 3 because the large number of thermocouples and observations make such indication extremely difficult; therefore, figure 4 is presented to show the deviation of the output of individual thermocouples from the values in the reference table. These plotted data are for four thermocouples selected at random. They are taken from the average of the observations obtained during both the ascending and decreasing temperature series. From the shapes of these deviation curves it is obvious that for precision thermometry these thermocouples will have to be calibrated at many different temperatures. Not one of the test thermocuples exhibits a linear deviation curve which makes corrections possible with only two calibration points. This is not too surprising since few thermocouples exhibit this desirable characteristic. In this case the lack of linearity is probably due to a shift in calibration during the calibration experiments. In some cases there was considerable change in output between two measurements, one of which was obtained from the increasing and the other from the decreasing temperature series. This change in calibration is shown clearly in figure 5 in which each plotted point is the difference in output between observations obtained at a particular temperature during the increasing and decreasing temperature series. Although this plot is for all of the thermocouples made from the wire of Lot B only it is quite similar to those for Lots $\mathrm{A}$ and $\mathrm{C}$. There are two major points of similarity: (1), thermocouples from all three lots experienced the greatest change in output at about $1000{ }^{\circ} \mathrm{F}$; (2) there was a change in sign in the calibration shift of many of the thermocouples in the range of temperatures between 500 and $1000{ }^{\circ} \mathrm{F}$. Upon examination of figure 4 it will be noted that the change in slope of most of the deviation curves also occurs in this same temperature range. It is possible that the change in calibration shown in figure 5 and the change in slope of the deviation curves in figure 4 are the result of some change in one or both of the Platinel alloys. According to a survey by Vines [9] the palladium gold system appears to consist of a continuous series of solid solutions free from transformation in the solid state. However, a peculiar change in the slope of the electrical resistivity and temperature coefficient of electrical resistivity curves in the neighborhood of 70 percent gold has not been explained. This is very close to the composition of the negative element which consists of 65 percent gold and 35 percent palladium.

In some earlier work [5] in which the emf of the individual elements against platinum were measured, the negative element (1503) underwent the greatest change when aged at $2300{ }^{\circ} \mathrm{F}$ for $1500 \mathrm{hr}$. The situation was reversed in the case of the elements aged at 1900 and $2200{ }^{\circ} \mathrm{F}$ for $1500 \mathrm{hr}$. At these aging temperatures the changes in emf of the positive elements (1813) were considerably greater than those of the negative. In this more recent work the emf of the alloy 1813 versus platinum showed the smaller change in emf. In this case the maximum temperature to which the elements were exposed was $2300{ }^{\circ} \mathrm{F}$ and for at most only about $1 / 2 \mathrm{hr}$.

There are also a few significant differences in the results of the later tests. The 40-mil thermocouples from Lots B and C suffered the greatest change in emf. From Lot A the 20-mil thermocouples experienced the greatest change while the 40-mil showed very little change. The maximum changes for any thermocouple from Lots $\mathrm{A}, \mathrm{B}$, and $\mathrm{C}$ were 61,74 , and $92 \mu \mathrm{V}$. With changes of this magnitude occurring during calibration the nonlinearity of the deviation curves as shown in figure 4 assumes lesser importance, particularly in the temperature range from 500 to $1000{ }^{\circ} \mathrm{F}$. In this region the maximum change in emf is about the same magnitude as the maximum deviation of the thermocouple emfs from the reference tables; therefore, corrections would be rather difficult to apply.

The long period and high-temperature anneal described in the section entitled Thermocouples was an effort to minimize such changes in the emf during calibration. This procedure was determined from much experience with several thermocouples and a comprehensive set of experiments with one 20-mil thermocouple. Following a determination of its emf at $2300^{\circ} \mathrm{F}$ it was heated electrically for $\frac{1}{2} \mathrm{hr}$ at $2400{ }^{\circ} \mathrm{F}$. Its emf was again determined at $2300{ }^{\circ} \mathrm{F}$. Emf determinations were repeated following additional heating periods of $1 / 2,1,1,3$, and $3 \mathrm{hr}$. The change in microvolts from the original emf is plotted versus the accumulated heating times in figure 6 . A large decrease in output after $1 / 2 \mathrm{hr}$ of heating is followed by a partial recovery during the next halfhour of heating. Additional heating results in further recovery. Although it is not shown for this thermocouple, prolonged heating will ultimately result in an output greater than the original. It is recognized that $90 \mathrm{~min}$ of heating is an inconvenient annealing time; however, this annealing period is considered necessary to eliminate the large emf changes that occur in these thermocouples during the first hour of heating.

The thermal emfs of the two Platinel elements versus the platinum leg of the standard thermocouple were developed from the averages of the observations obtained during the calibrations. Tables 2 and 3, thermal emfs of the elements versus Pt 27, were obtained by adjusting these values to compensate for the difference between $\mathrm{Pt} 27$ and the thermocouple platinum. The thermal emf developed between 1813 and Pt 27 is very low; thus, the emf developed between 1503 and $\mathrm{Pt} 27$ is very nearly equal to that of Platinel II. 1813 is thermoelectrically positive to $\mathrm{Pt} 27$ up to about $1675^{\circ} \mathrm{F}$ where it becomes negative. The negative element 1503 is negative to $\mathrm{Pt} 27$ from 32 to $2500^{\circ} \mathrm{F}$. These data in conjunction with a calibration of copper 


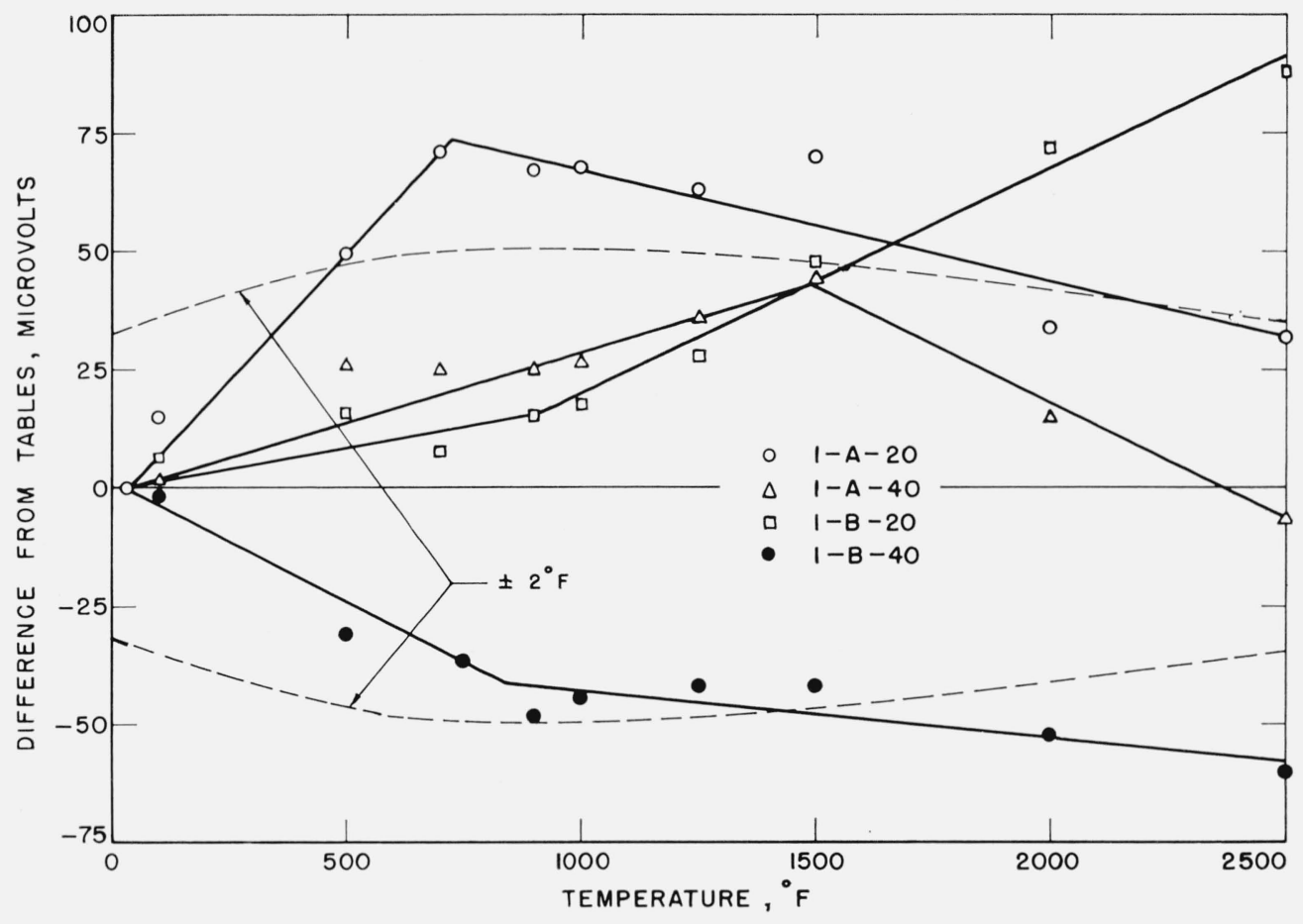

Figure 4. Differences between experimental and reference table values of thermal emf for four thermocouples.

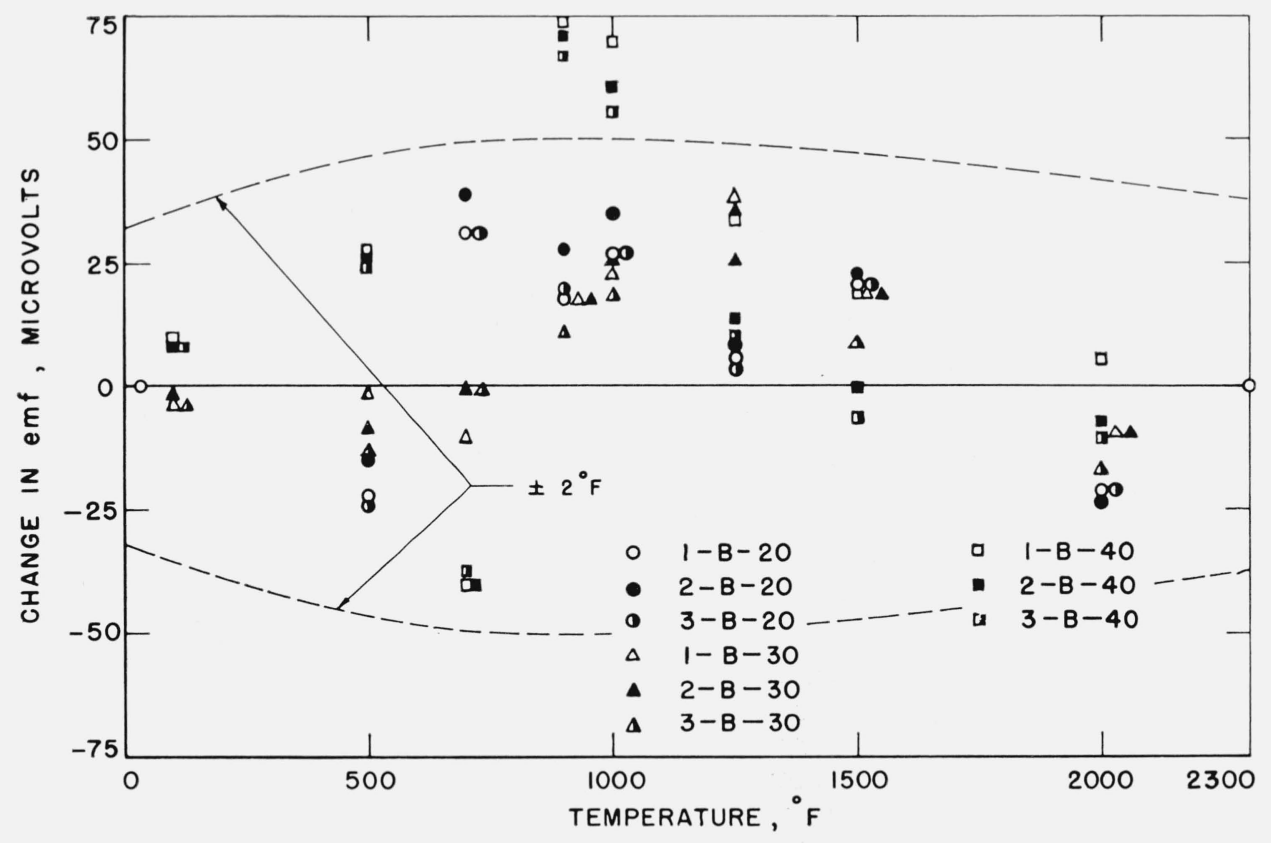

FiguRe 5. Change in thermal emf between determinations from increasing and decreasing temperature series. 


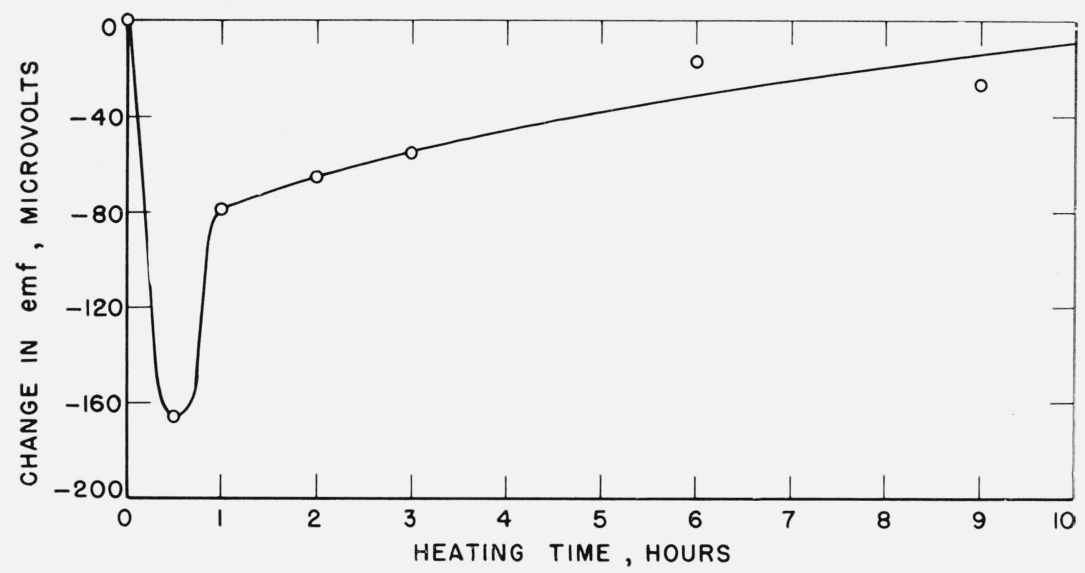

Figure 6. Change in thermal emf at $2300{ }^{\circ} \mathrm{F}$ as a function of heating time at $2400^{\circ} \mathrm{F}$.

TaBle 2. Thermal emf of 1503 versus Pt 27

Reference junctions at $32^{\circ} \mathrm{F}$.

\begin{tabular}{|c|c|c|c|}
\hline Temperature & Millivolts & Temperature & Millivolts \\
\hline${ }^{\circ} \mathrm{F}$ & & ${ }^{\circ} \mathrm{F}$ & \\
\hline 32 & 0.000 & 1400 & -31.285 \\
\hline 50 & -0.300 & 1450 & -32.534 \\
\hline 100 & -1.163 & 1500 & -33.777 \\
\hline 150 & -2.064 & 1550 & -35.016 \\
\hline 200 & -3.001 & 1600 & -36.249 \\
\hline 250 & -3.971 & 1650 & -37.476 \\
\hline 300 & -4.974 & 1700 & -38.697 \\
\hline 350 & -6.005 & 1750 & -39.909 \\
\hline 400 & -7.063 & 1800 & -41.114 \\
\hline 450 & -8.147 & 1850 & -42.309 \\
\hline 500 & -9.253 & 1900 & -43.496 \\
\hline 550 & -10.380 & 1950 & -44.673 \\
\hline 600 & -11.526 & 2000 & -45.840 \\
\hline 650 & -12.689 & 2050 & -46.997 \\
\hline 700 & -13.869 & 2100 & -48.145 \\
\hline 750 & -15.063 & 2150 & -49.282 \\
\hline 800 & -16.269 & 2200 & -50.407 \\
\hline 850 & -17.488 & 2250 & -51.521 \\
\hline 900 & -18.718 & 2300 & -52.624 \\
\hline 950 & -19.956 & 2350 & -53.715 \\
\hline 1000 & -21.201 & 2400 & -54.794 \\
\hline 1050 & -22.453 & 2450 & -55.861 \\
\hline 1100 & -23.711 & 2500 & -56.916 \\
\hline 1150 & -24.977 & & \\
\hline 1200 & -26.246 & & \\
\hline 1250 & -27.510 & & \\
\hline $\begin{array}{l}1300 \\
1350\end{array}$ & $\begin{array}{l}-28.772 \\
-30.031\end{array}$ & & \\
\hline & & & \\
\hline
\end{tabular}

versus $\mathrm{Pt} 27$ furnished the data for the construction of table $5 \mathrm{~A}$, which presents the thermal emf of copper versus 1503 and 1813 from 32 to $500^{\circ} \mathrm{F}$. These values are often necessary when thermocouple cold junctions are at temperatures other than $32^{\circ} \mathrm{F}$. The values for 1503,1813 , and copper versus $\mathrm{Pt} 27$ are given in $25^{\circ} \mathrm{F}$ intervals in table $5 \mathrm{~A}$. The copper versus $\mathrm{Pt} 27$ values are in excellent agreement with those of Roeser and Dahl [10] which were reported to the nearest $10 \mu \mathrm{V}$. It will be noted that copper is thermoelectrically positive to $\mathrm{Pt} 27$ and to both elements of Platinel II.

One of the aims in the design of Platinel II was to develop a thermocouple having essentially the same
Table 3. Thermal emf of 1813 versus Pt 27 Reference junctions at $32{ }^{\circ} \mathrm{F}$.

\begin{tabular}{|c|c|c|c|}
\hline Temperature & Millivolts & Temperature & Millivolts \\
\hline${ }^{\circ} \mathrm{F}$ & & ${ }^{\circ} \mathrm{F}$ & \\
\hline 32 & 0.000 & 1400 & .445 \\
\hline 50 & 0.001 & 1450 & .385 \\
\hline 100 & .010 & 1500 & .318 \\
\hline 150 & .030 & 1550 & .243 \\
\hline 200 & .059 & 1600 & .161 \\
\hline 250 & .095 & 1650 & .071 \\
\hline 300 & .136 & 1700 & -.026 \\
\hline 350 & .182 & 1750 & -.129 \\
\hline 400 & .231 & 1800 & -.238 \\
\hline 450 & .281 & 1850 & -.353 \\
\hline 500 & .331 & 1900 & -.474 \\
\hline 550 & .381 & 1950 & -.600 \\
\hline 600 & .430 & 2000 & -.732 \\
\hline 650 & .476 & 2050 & -.870 \\
\hline 700 & .518 & 2100 & -1.014 \\
\hline 750 & .556 & 2150 & -1.163 \\
\hline 800 & .589 & 2200 & -1.317 \\
\hline 850 & .616 & 2250 & -1.476 \\
\hline 900 & .637 & 2300 & -1.640 \\
\hline 950 & .651 & 2350 & -1.809 \\
\hline 1000 & .658 & 2400 & -1.983 \\
\hline 1050 & .658 & 2450 & -2.162 \\
\hline 1100 & .651 & 2500 & -2.345 \\
\hline 1150 & .637 & & \\
\hline 1200 & .651 & & \\
\hline 1250 & .585 & & \\
\hline $\begin{array}{l}1300 \\
1350\end{array}$ & $\begin{array}{r}546 \\
499\end{array}$ & & \\
\hline & .780 & & \\
\hline
\end{tabular}

thermal-emf relation as Chromel-Alumel. ${ }^{3}$ Table 4 shows a comparison of the thermal emf of Platinel II and Chromel-Alumel from NBS Circular 561 over the entire range of calibration in increments of $50{ }^{\circ} \mathrm{F}$. The third column is the difference in degrees $\mathrm{F}$ indicated by the two thermocouples if the ChromelAlumel reference table is used for both. The thermocouples develop identical thermal emfs at 32,1300 , and $2225^{\circ} \mathrm{F}$. Between 1000 and $2500{ }^{\circ} \mathrm{F}$ the maximum difference between the two thermocouples is only $18^{\circ} \mathrm{F}$.

3 Registered Trademark of Hoskins Manufacturing Co. 
Table 4. Comparison of Platinel II with

Chromel-Alumel thermocouple

Reference junctions at $32^{\circ} \mathrm{F}$.

\begin{tabular}{|c|c|c|c|}
\hline Temperature & Platinel II & $\begin{array}{c}\text { Chromel- } \\
\text { Alumel }\end{array}$ & Difference* \\
\hline $\begin{array}{r}{ }^{\circ} F \\
-150 \\
-100 \\
-50 \\
0\end{array}$ & $\begin{aligned} & m V \\
&- 2.603 \\
&-1.974 \\
&-1.277 \\
&-0.517\end{aligned}$ & $\begin{array}{c}m V \\
-3.52 \\
-2.65 \\
-1.70 \\
-0.68\end{array}$ & $\begin{array}{r}{ }^{\circ} F \\
+53 \\
+36 \\
+21 \\
+8\end{array}$ \\
\hline $\begin{array}{r}32 \\
50 \\
100 \\
150\end{array}$ & $\begin{array}{l}0.000 \\
0.301 \\
1.173 \\
2.094\end{array}$ & $\begin{array}{l}0.00 \\
0.40 \\
1.52 \\
2.66\end{array}$ & $\begin{array}{r}0 \\
-4 \\
-15 \\
-25\end{array}$ \\
\hline $\begin{array}{l}200 \\
250 \\
300 \\
350\end{array}$ & $\begin{array}{l}3.060 \\
4.066 \\
5.110 \\
6.187\end{array}$ & $\begin{array}{l}3.82 \\
4.97 \\
6.09 \\
7.20\end{array}$ & $\begin{array}{l}-33 \\
-39 \\
-44 \\
-46\end{array}$ \\
\hline $\begin{array}{l}400 \\
450 \\
500 \\
550\end{array}$ & $\begin{array}{r}7.294 \\
8.428 \\
9.584 \\
10.761\end{array}$ & $\begin{array}{r}8.31 \\
9.43 \\
10.57 \\
11.71\end{array}$ & $\begin{array}{l}-46 \\
-45 \\
-44 \\
-41\end{array}$ \\
\hline $\begin{array}{l}600 \\
650 \\
700 \\
750\end{array}$ & $\begin{array}{l}11.956 \\
13.165 \\
14.387 \\
15.619\end{array}$ & $\begin{array}{l}12.86 \\
14.02 \\
15.18 \\
16.35\end{array}$ & $\begin{array}{l}-39 \\
-37 \\
-34 \\
-31\end{array}$ \\
\hline $\begin{array}{l}800 \\
850 \\
900 \\
950\end{array}$ & $\begin{array}{l}16.858 \\
18.104 \\
19.355 \\
20.607\end{array}$ & $\begin{array}{l}17.53 \\
18.70 \\
19.89 \\
21.07\end{array}$ & $\begin{array}{l}-28 \\
-26 \\
-22 \\
-20\end{array}$ \\
\hline $\begin{array}{l}1000 \\
1050 \\
1100 \\
1150\end{array}$ & $\begin{array}{l}21.859 \\
23.110 \\
24.362 \\
25.614\end{array}$ & $\begin{array}{l}22.26 \\
23.44 \\
24.63 \\
25.81\end{array}$ & $\begin{array}{r}-17 \\
-14 \\
-11 \\
-8\end{array}$ \\
\hline $\begin{array}{l}1200 \\
1250 \\
1300 \\
1350\end{array}$ & $\begin{array}{l}26.861 \\
28.095 \\
29.318 \\
30.529\end{array}$ & $\begin{array}{l}26.98 \\
28.15 \\
29.32 \\
30.49\end{array}$ & $\begin{array}{r}-5 \\
-2 \\
0 \\
+2\end{array}$ \\
\hline $\begin{array}{l}1400 \\
1450 \\
1500 \\
1550\end{array}$ & $\begin{array}{l}31.730 \\
32.919 \\
34.095 \\
35.259\end{array}$ & $\begin{array}{l}31.65 \\
32.80 \\
33.93 \\
35.07\end{array}$ & $\begin{array}{l}+3 \\
+5 \\
+7 \\
+8\end{array}$ \\
\hline $\begin{array}{l}1600 \\
1650 \\
1700 \\
1750\end{array}$ & $\begin{array}{l}36.410 \\
37.547 \\
38.671 \\
39.780\end{array}$ & $\begin{array}{l}36.19 \\
37.31 \\
38.43 \\
39.53\end{array}$ & $\begin{array}{l}+9 \\
+10 \\
+11 \\
+12\end{array}$ \\
\hline $\begin{array}{l}1800 \\
1850 \\
1900 \\
1950\end{array}$ & $\begin{array}{l}40.876 \\
41.956 \\
43.022 \\
44.072\end{array}$ & $\begin{array}{l}40.62 \\
41.70 \\
42.78 \\
43.85\end{array}$ & $\begin{array}{l}+12 \\
+12 \\
+11 \\
+10\end{array}$ \\
\hline $\begin{array}{l}2000 \\
2050 \\
2100 \\
2150\end{array}$ & $\begin{array}{l}45.108 \\
46.127 \\
47.131 \\
48.119\end{array}$ & $\begin{array}{l}44.91 \\
45.96 \\
47.00 \\
48.03\end{array}$ & $\begin{array}{r}+10 \\
+8 \\
+6 \\
+4\end{array}$ \\
\hline $\begin{array}{l}2200 \\
2250 \\
2300 \\
2350\end{array}$ & $\begin{array}{l}49.090 \\
50.045 \\
50.984 \\
51.906\end{array}$ & $\begin{array}{l}49.05 \\
50.06 \\
51.05 \\
52.03\end{array}$ & $\begin{array}{l}+2 \\
-1 \\
-4 \\
-7\end{array}$ \\
\hline $\begin{array}{l}2400 \\
2450 \\
2500\end{array}$ & $\begin{array}{l}52.811 \\
53.699 \\
54.571\end{array}$ & $\begin{array}{l}53.01 \\
53.97 \\
54.92\end{array}$ & $\begin{array}{l}-10 \\
-14 \\
-18\end{array}$ \\
\hline
\end{tabular}

*Temperature difference based on Chromel-Alumel table in NBS Circular 561.

\section{Conclusions}

It should be remembered that the reference tables cited herein were determined from the average values of 27 thermocouples of three wire diameters from three lots each of positive and negative alloys. Although the tables when plotted represent the shape of the temperature-emf curve for Platinel II very well, they cannot be depended upon to provide a calibration curve or temperature-emf relationship for a particular thermocouple. Usually these tables, when used in conjunction with any typical undamaged Platinel II thermocouple, will provide temperatures which are not in error by more than 3,5 , and $10{ }^{\circ} \mathrm{F}$ at 500,1000 , and $2500{ }^{\circ} \mathrm{F}$ respectively. These errors can be reduced somewhat with deviation curves determined by calibration at several points such as 500, 1000, 1500 , and $2500{ }^{\circ} \mathrm{F}$. The maximum error in this case is probably about $6^{\circ} \mathrm{F}$. This can be further reduced if the maximum temperature to which the thermocouple is exposed is reduced below $2300{ }^{\circ} \mathrm{F}$. As shown in [5], thermoelectric stability is greatly improved by a reduction in maximum temperature.

The authors thank Miss J. A. Speckman of the Statistical Engineering Section of the Applied Mathematics Division for her assistance in the determination of the three equations from which these reference tables are developed. They are also indebted to Mrs. M. R. Massie and Mrs. C. S. Watkins, of the Temperature Physics Section, who made all measurements below $25^{\circ} \mathrm{C}\left(77^{\circ} \mathrm{F}\right)$.

\section{References}

[1] D. J. Accinno and J. F. Schneider, Platinel-A noble metal thermocouple to replace Chromel-Alumel, Engelhard Industries, Inc. Tech. Bull. 1, No. 2, 53 (Sept. 1960).

[2] D. J. Accinno and J. F. Schneider, Platinel: A noble metal thermocouple, Temperature - Its Measurement and Control in Science and Industry $\mathbf{3}$ (ed., C. M. Herzfeld), Part 2 (ed. A. I. Dahl), p. 195, Reinhold Publ. Corp., New York (1962).

[3] E. D. Zysk, A review of recent work with the Platinel thermocouple, Engelhard Industries, Inc. Tech. Bull. 4, No. 1, 5 (June 1963).

[4] H. J. Greenberg and E. D. Zysk, Applied research fabrication and testing of $2300^{\circ} \mathrm{F}$ thermocouple for airbreathing propulsion systems, WADC Tech. Doc. Rept. ASD-TDR-62-891 (Jan. 1963).

[5] P. D. Freeze and L. O. Olsen, Thermoelectric and mechanical stability of Platinel II thermocouples in oxidizing atmospheres, WADC Tech. Doc. Rept. ASD-TDR-62-835 (Nov. 1962).

[6] H. Shenker, J. I. Lauritzen, R. J. Corruccini, and S. T. Lonberger, Reference tables for thermocouples, NBS Circ. 561, 1 (1955).

[7] W. F. Roeser and S. T. Lonberger, Methods of testing thermocouples and thermocouple materials, NBS Circ. 590 (1958); NBS Handb. 77, 2, 88 (1961).

[8] R. P. Benedict and H. F. Ashby, Improved reference tables for thermocouples, Temperature-Its Measurement and Control in Science and Industry $\mathbf{3}$ (ed. C. M. Herzfeld), Part 2 (ed. A. I. Dahl), p. 51, Reinhold Publ. Corp., New York (1962).

[9] R. F. Vines, The platinum metals and their alloys, ed E. M. Wise, The International Nickel Company, Inc., New York, N.Y. (1941).

[10] W. F. Roeser and A. I. Dahl, Reference tables for ironconstantan and copper-constantan thermocouples, J. Res. NBS 20, 337 (1938) RP1080.

[11] J. M. Cameron and J. Hilsenrath, Use of general purpose coding systems for statistical calculations, Proc. IBM Scientific Computing Symp. on Statistics held October 21-23, 1963 (In press). 
Appendix

Table 1A. Platinel II, millivolts versus degrees Celsiug (centigrade)

Electromotive force in absolute millivolts. Temperature in degrees C (Int. 1948). Reference junctions at $0^{\circ} \mathrm{C}$.

\begin{tabular}{|c|c|c|c|c|c|c|c|c|c|c|c|c|}
\hline Millivolts & .000 & .100 & .200 & .300 & .400 & .500 & .600 & .700 & .800 & .900 & 1.000 & Millivolts \\
\hline \multirow{3}{*}{$\begin{array}{l}-2.000 \\
-1.000\end{array}$} & \multicolumn{11}{|c|}{ Degrees C } & \multirow{4}{*}{$\begin{array}{l}-2.000 \\
-1.000\end{array}$} \\
\hline & -74.4 & -78.6 & -82.9 & -87.3 & -91.8 & -96.3 & -100.9 & -- & -- & -- & - & \\
\hline & -35.2 & -38.9 & -42.6 & -46.4 & -50.3 & -54.2 & -58.1 & -62.1 & -66.1 & $* 70.2$ & -74.4 & \\
\hline-0.000 & 0.0 & -3.4 & -6.8 & -10.2 & -13.7 & -17.2 & -20.7 & -24.3 & -27.9 & -31.5 & -35.2 & \\
\hline+0.000 & 0.0 & 3.4 & 6.7 & 10.0 & 13.2 & 16.5 & 19.7 & 22.9 & 26.1 & 29.3 & 32.4 & +0.000 \\
\hline 1.000 & 32.4 & 35.5 & 38.6 & 41.7 & 44.8 & 47.8 & 50.8 & 53.9 & 56.9 & 59.8 & 62.8 & 1.000 \\
\hline 2.000 & 62.8 & 65.7 & 68.7 & 71.6 & 74.5 & 77.4 & 80.3 & 83.1 & 86.0 & 88.8 & 91.7 & 2.000 \\
\hline 3.000 & 91.7 & 94.5 & 97.3 & 100.1 & 102.8 & 105.6 & 108.4 & 111.1 & 113.9 & 116.6 & 119.3 & 3.000 \\
\hline 4.000 & 119.4 & 122.0 & 124.7 & 127.4 & 130.1 & 132.8 & 135.4 & 138.1 & 140.7 & 143.4 & 146.0 & 4.000 \\
\hline 5.000 & 146.0 & 148.6 & 151.2 & 153.8 & 156.4 & 159.0 & 161.6 & 164.2 & 166.8 & 169.3 & 171.9 & 5.000 \\
\hline 6.000 & 171.9 & 174.4 & 177.0 & 179.5 & 182.1 & 184.6 & 187.1 & 189.6 & 192.1 & 194.6 & 197.1 & 6.000 \\
\hline 7.000 & 197.1 & 199.6 & 202.1 & 204.6 & 207.1 & 209.5 & 212.0 & 214.5 & 216.9 & 219.4 & 221.9 & 7.000 \\
\hline 8.000 & 221.9 & 224.3 & 226.7 & 229.1 & 231.6 & 234.0 & 236.4 & 238.8 & 241.2 & 243.6 & 246.0 & 8.000 \\
\hline 9.000 & 246.0 & 248.4 & 250.8 & 253.2 & 255.6 & 258.0 & 260.4 & 262.8 & 265.1 & 267.5 & 269.9 & 9.000 \\
\hline 10.000 & 269.9 & 272.2 & 274.6 & 276.9 & 279.3 & 281.6 & 284.0 & 286.3 & 288.7 & 291.0 & 293.4 & 10.000 \\
\hline 11.000 & 293.4 & 295.7 & 298.0 & 300.4 & 302.7 & 305.0 & 307.3 & 309.6 & 312.0 & 314.3 & 316.6 & 11.000 \\
\hline 12.000 & 316.6 & 318.9 & 321.2 & 323.5 & 325.8 & 328.1 & 330.4 & 332.7 & 335.0 & 337.3 & 339.6 & 12.000 \\
\hline 13.000 & 339.6 & 341.8 & 344.1 & 346.4 & 348.7 & 351.0 & 353.3 & 355.5 & 357.8 & 360.1 & 362.3 & 13.000 \\
\hline 14.000 & 362.3 & 364.6 & 366.9 & 369.1 & 371.4 & 373.7 & 375.9 & 378.2 & 380.5 & 382.7 & 385.0 & 14.000 \\
\hline 15.000 & 385.0 & 387.2 & 389.5 & 391.7 & 394.0 & 396.2 & 398.5 & 400.7 & 403.0 & 405.2 & 407.5 & 15.000 \\
\hline 16.000 & 407.5 & 409.7 & 411.9 & 414.2 & 416.4 & 418.7 & 420.9 & 423.1 & 425.4 & 427.6 & 429.8 & 16.000 \\
\hline 17.000 & 429.8 & 432.1 & 434.3 & 436.5 & 438.8 & 441.0 & 443.2 & 445.4 & 447.7 & 449.9 & 452.1 & 17.000 \\
\hline 18.000 & 452.1 & 454.4 & 456.6 & 458.8 & 461.0 & 463.2 & 465.5 & 468.7 & 469.9 & 472.1 & 474.3 & 18.000 \\
\hline 19.000 & 474.3 & 476.6 & 478.8 & 481.0 & 483.2 & 485.4 & 487.7 & 489.9 & 492.1 & 494.3 & 496.5 & 19.000 \\
\hline 20.000 & 496.5 & 498.8 & 501.0 & 503.2 & 505.4 & 507.6 & 509.9 & 512.1 & 514.3 & 516.5 & 518.7 & 20.000 \\
\hline 21.000 & 518.7 & 520.9 & 523.2 & 525.4 & 527.6 & 529.8 & 532.0 & 534.3 & 536.5 & 538.7 & 540.9 & 21.000 \\
\hline 22.000 & 540.9 & 543.1 & 545.4 & 547.6 & 549.8 & 552.0 & 554.2 & 556.4 & 558.7 & 560.9 & 563.1 & 22.000 \\
\hline 23.000 & 563.1 & 565.3 & 567.5 & 569.8 & 572.0 & 574.2 & 576.4 & 578.6 & 580.9 & 583.1 & 585.3 & 23.000 \\
\hline 24.000 & 585.3 & 587.5 & 589.7 & 591.9 & 594.2 & 596.4 & 598.6 & 600.8 & 603.0 & 605.3 & 607.5 & 24.000 \\
\hline 25.000 & 607.5 & 609.7 & 611.9 & 614.1 & 616.4 & 618.6 & 620.8 & 623.0 & 625.2 & 627.5 & 629.7 & 25.000 \\
\hline 26.000 & 629.7 & 631.9 & 634.1 & 636.3 & 638.6 & 640.8 & 643.0 & 645.3 & 647.5 & 649.8 & 652.0 & 26.000 \\
\hline 27.000 & 652.0 & 654.3 & 656.5 & 658.7 & 661.0 & 663.2 & 665.5 & 667.8 & 670.0 & 672.3 & 674.5 & 27.000 \\
\hline 28.000 & 674.5 & 676.8 & 679.1 & 681.3 & 683.6 & 685.8 & 688.1 & 690.4 & 692.7 & 694.9 & 697.2 & 28.000 \\
\hline 29.000 & 697.2 & 699.5 & 701.8 & 704.0 & 706.3 & 708.6 & 710.9 & 713.2 & 715.5 & 717.8 & 720.1 & 29.000 \\
\hline 30.000 & 720.1 & 722.3 & 724.6 & 726.9 & 729.2 & 731.5 & 733.8 & 736.2 & 738.5 & 740.8 & 743.1 & 30.000 \\
\hline 31.000 & 743.1 & 745.4 & 747.7 & 750.0 & 752.3 & 754.7 & 757.0 & 759.3 & 761.6 & 764.0 & 766.3 & 31.000 \\
\hline 32.000 & 766.3 & 768.6 & 770.9 & 773.3 & 775.6 & 778.0 & 780.3 & 782.6 & 785.0 & 787.3 & 789.7 & 32.000 \\
\hline 33.000 & 789.7 & 792.0 & 794.4 & 796.7 & 799.1 & 801.5 & 803.8 & 806.2 & 808.6 & 810.9 & 813.3 & 33.000 \\
\hline 34.000 & 813.3 & 815.7 & 818.0 & 820.4 & 822.8 & 825.2 & 827.6 & 830.0 & 832.3 & 834.7 & 837.1 & 34.000 \\
\hline 35.000 & 837.1 & 839.5 & 841.9 & 844.3 & 846.7 & 849.1 & 851.5 & 853.9 & 856.4 & 858.8 & 861.2 & 35.000 \\
\hline 36.000 & 861.2 & 863.6 & 866.0 & 868.5 & 870.9 & 873.3 & 875.7 & 878.2 & 880.6 & 883.0 & 885.5 & 36.000 \\
\hline 37.000 & 885.5 & 887.9 & 890.4 & 892.8 & 895.3 & 897.7 & 900.2 & 902.7 & 905.1 & 907.6 & 910.0 & 37.000 \\
\hline 38.000 & 910.0 & 912.5 & 915.0 & 917.5 & 919.9 & 922.4 & 924.9 & 927.4 & 929.9 & 932.4 & 934.9 & 38.000 \\
\hline 39.000 & 934.9 & 937.4 & 939.9 & 942.4 & 944.9 & 947.4 & 949.9 & 952.4 & 954.9 & 957.5 & 960.0 & 39.000 \\
\hline 40.000 & 960.0 & 962.5 & 965.0 & 967.6 & 970.1 & 972.7 & 975.2 & 977.7 & 980.3 & 982.8 & 985.4 & 40.000 \\
\hline 41.000 & 985.4 & 988.0 & 990.5 & 993.1 & 995.7 & 998.2 & 1000.8 & 1003.4 & 1006.0 & 1008.5 & 1011.1 & 41.000 \\
\hline 42.000 & 1011.1 & 1013.7 & 1016.3 & 1018.9 & 1021.5 & 1024.1 & 1026.7 & 1029.3 & 1032.0 & 1034.6 & 1037.2 & 42.000 \\
\hline 43.000 & 1037.2 & 1039.8 & 1042.5 & 1045.1 & 1047.7 & 1050.4 & 1053.0 & 1055.7 & 1058.3 & 1061.0 & 1063.6 & 43.000 \\
\hline 44.000 & 1063.6 & 1066.3 & 1069.0 & 1071.6 & 1074.3 & 1077.0 & 1079.7 & 1082.3 & 1085.0 & 1087.7 & 1090.4 & 44.000 \\
\hline 45.000 & 1090.4 & 1093.1 & 1095.8 & 1098.5 & 1101.3 & 1104.0 & 1106.7 & 1109.4 & 1112.1 & 1114.9 & 1117.6 & 45.000 \\
\hline 46.000 & 1117.6 & 1120.4 & 1123.1 & 1125.9 & 1128.6 & 1131.4 & 1134.1 & 1136.9 & 1139.7 & 1142.5 & 1145.2 & 46.000 \\
\hline 47.000 & 1145.2 & 1148.0 & 1150.8 & 1153.6 & 1156.4 & 1159.2 & 1162.0 & 1164.8 & 1167.7 & 1170.5 & 1173.3 & 47.000 \\
\hline 48.000 & 1173.3 & 1176.1 & 1179.0 & 1181.8 & 1184.7 & 1187.5 & 1190.4 & 1193.2 & 1196.1 & 1199.0 & 1201.9 & 48.000 \\
\hline 49.000 & 1201.9 & 1204.7 & 1207.6 & 1210.5 & 1213.4 & 1216.3 & 1219.2 & 1222.1 & 1225.0 & 1228.0 & 1230.9 & 49.000 \\
\hline 50.000 & 1230.9 & 1233.8 & 1236.8 & 1239.7 & 1242.7 & 1245.6 & 1248.6 & 1251.6 & 1254.5 & 1257.5 & 1260.5 & 50.000 \\
\hline 51.000 & 1260.5 & 1263.5 & 1266.5 & 1269.5 & 1272.5 & 1275.5 & 1278.5 & 1281.5 & 1284.6 & 1287.6 & 1290.6 & 51.000 \\
\hline 52.000 & 1290.6 & 1293.7 & 1296.8 & 1299.8 & 1302.9 & 1306.0 & 1309.0 & 1312.1 & 1315.2 & 1318.3 & 1321.4 & 52.000 \\
\hline 53.000 & 1321.4 & 1324.5 & 1327.7 & 1330.8 & 1333.9 & 1337.1 & 1340.2 & 1343.4 & 1346.5 & 1349.7 & 1352.9 & 53.000 \\
\hline 54.000 & 1352.9 & 1356.0 & 1359.2 & 1362.4 & 1365.6 & 1368.8 & 1372.0 & -- & -- & -- & -- & 54.000 \\
\hline llivolts & .000 & .100 & .200 & .300 & .400 & .500 & .600 & .700 & .800 & .900 & 1.000 & Millivolts \\
\hline
\end{tabular}


Table 2A. Platinel II, degrees Celsius versus millivolts

Electromotive force in absolute millivolts. Temperature in degrees C (Int. 1948). Reference junctions at $0^{\circ} \mathrm{C}$.

\begin{tabular}{|c|c|c|c|c|c|c|c|c|c|c|c|c|}
\hline${ }^{\circ} \mathrm{C}$ & 0 & 1 & 2 & 3 & 4 & 5 & 6 & 7 & 8 & 9 & 10 & ${ }^{\circ} \mathrm{C}$ \\
\hline & \multicolumn{11}{|c|}{ Millivolts } & \\
\hline-90 & -2.360 & -2.383 & -2.405 & -2.427 & -2.449 & -2.471 & -2.493 & -2.515 & -2.537 & -2.558 & -2.580 & -90 \\
\hline-80 & -2.132 & -2.155 & -2.178 & -2.201 & -2.224 & -2.247 & -2.270 & -2.293 & -2.315 & -2.338 & -2.360 & -80 \\
\hline-70 & -1.894 & -1.918 & -1.942 & -1.966 & -1.990 & -2.014 & -2.038 & -2.061 & -2.085 & -2.108 & -2.132 & -70 \\
\hline-60 & -1.648 & -1.673 & -1.698 & -1.723 & -1.747 & -1.772 & -1.797 & -1.821 & -1.846 & -1.870 & -1.894 & -60 \\
\hline-50 & -1.393 & -1.419 & -1.445 & -1.470 & -1.496 & -1.522 & -1.547 & -1.572 & -1.598 & -1.623 & -1.648 & -50 \\
\hline-40 & -1.130 & -1.157 & -1.183 & -1.210 & -1.236 & -1.263 & -1.289 & -1.315 & -1.341 & -1.367 & -1.393 & -40 \\
\hline-30 & -0.859 & -0.887 & -0.914 & -0.941 & -0.968 & -0.996 & -1.023 & -1.050 & -1.077 & -1.103 & -1.130 & -30 \\
\hline-20 & -0.580 & -0.608 & -0.637 & -0.665 & -0.693 & -0.721 & -0.748 & -0.776 & -0.804 & -0.832 & -0.859 & -20 \\
\hline-10 & -0.294 & -0.323 & -0.352 & -0.381 & -0.409 & -0.438 & -0.467 & -0.495 & -0.524 & -0.552 & -0.580 & -10 \\
\hline-0 & -0.000 & -0.030 & -0.059 & -0.089 & -0.118 & -0.148 & -0.177 & -0.206 & -0.236 & -0.265 & -0.294 & -0 \\
\hline+0 & 0.000 & 0.030 & 0.060 & 0.090 & 0.120 & 0.150 & 0.180 & 0.210 & 0.240 & 0.271 & 0.301 & +0 \\
\hline 10 & 0.301 & 0.331 & 0.362 & 0.393 & 0.423 & 0.454 & 0.485 & 0.516 & 0.547 & 0.578 & 0.609 & 10 \\
\hline 20 & 0.609 & 0.640 & 0.671 & 0.703 & 0.734 & 0.765 & 0.797 & 0.828 & 0.860 & 0.892 & 0.923 & 20 \\
\hline 30 & 0.923 & 0.955 & 0.987 & 1.019 & 1.051 & 1.083 & 1.115 & 1.148 & 1.180 & 1.212 & 1.245 & 30 \\
\hline 40 & 1.245 & 1.277 & 1.310 & 1.342 & 1.375 & 1.408 & 1.440 & 1.473 & 1.506 & 1.539 & 1.572 & 40 \\
\hline 50 & 1.572 & 1.605 & 1.638 & 1.672 & 1.705 & 1.738 & 1.772 & 1.805 & 1.839 & 1.872 & 1.906 & 50 \\
\hline 60 & 1.906 & 1.939 & 1.973 & 2.007 & 2.041 & 2.075 & 2.109 & 2.143 & 2.177 & 2.211 & 2.245 & 60 \\
\hline 70 & 2.245 & 2.280 & 2.314 & 2.348 & 2.383 & 2.417 & 2.452 & 2.486 & 2.521 & 2.556 & 2.591 & 70 \\
\hline 80 & 2.591 & 2.625 & 2.660 & 2.695 & 2.730 & 2.765 & 2.800 & 2.836 & 2.871 & 2.906 & 2.941 & 80 \\
\hline 90 & 2.941 & 2.977 & 3.012 & 3.048 & 3.083 & 3.119 & 3.154 & 3.190 & 3.226 & 3.262 & 3.298 & 90 \\
\hline 100 & 3.298 & 3.334 & 3.369 & 3.405 & 3.442 & 3.478 & 3.514 & 3.550 & 3.586 & 3.623 & 3.659 & 100 \\
\hline 110 & 3.659 & 3.695 & 3.732 & 3.768 & 3.805 & 3.842 & 3.878 & 3.915 & 3.952 & 3.988 & 4.025 & 110 \\
\hline 120 & 4.025 & 4.062 & 4.099 & 4.136 & 4.173 & 4.210 & 4.247 & 4.285 & 4.322 & 4.359 & 4.397 & 120 \\
\hline 130 & 4.397 & 4.434 & 4.471 & 4.509 & 4.546 & 4.584 & 4.621 & 4.659 & 4.697 & 4.735 & 4.772 & 130 \\
\hline 140 & 4.772 & 4.810 & 4.848 & 4.886 & 4.924 & 4.962 & 5.000 & 5.038 & 5.076 & 5.114 & 5.153 & 140 \\
\hline 150 & 5.153 & 5.191 & 5.229 & 5.268 & 5.306 & 5.344 & 5.383 & 5.421 & 5.460 & 5.499 & 5.537 & 150 \\
\hline 160 & 5.537 & 5.576 & 5.615 & 5.653 & 5.692 & 5.731 & 5.770 & 5.809 & 5.848 & 5.887 & 5.926 & 160 \\
\hline 170 & 5.926 & 5.965 & 6.004 & 6.043 & 6.083 & 6.122 & 6.161 & 6.200 & 6.240 & 6.279 & 6.319 & 170 \\
\hline 180 & 6.319 & 6.358 & 6.398 & 6.437 & 6.477 & 6.516 & 6.556 & 6.596 & 6.636 & 6.675 & 6.715 & 180 \\
\hline 190 & 6.715 & 6.755 & 6.795 & 6.835 & 6.875 & 6.915 & 6.955 & 6.995 & 7.035 & 7.075 & 7.115 & 190 \\
\hline 200 & 7.115 & 7.155 & 7.196 & 7.236 & 7.276 & 7.317 & 7.357 & 7.397 & 7.438 & 7.478 & 7.519 & 200 \\
\hline 210. & 7.519 & 7.559 & 7.600 & 7.641 & 7.681 & 7.722 & 7.763 & 7.803 & 7.844 & 7.885 & 7.926 & 210 \\
\hline 220 & 7.926 & 7.967 & 8.008 & 8.049 & 8.090 & 8.131 & 8.172 & 8.213 & 8.254 & 8.295 & 8.336 & 220 \\
\hline 230 & 8.336 & 8.377 & 8.418 & 8.460 & 8.501 & 8.542 & 8.584 & 8.625 & 8.666 & 8.708 & 8.749 & 230 \\
\hline 240 & 8.749 & 8.791 & 8.832 & 8.874 & 8.915 & 8.957 & 8.999 & 9.040 & 9.082 & 9.124 & 9.165 & 240 \\
\hline 250 & 9.165 & 9.207 & 9.249 & 9.291 & 9.333 & 9.375 & 9.416 & 9.458 & 9.500 & 9.542 & 9.584 & 250 \\
\hline 260 & 9.584 & 9.626 & 9.668 & 9.711 & 9.753 & 9.795 & 9.837 & 9.879 & 9.921 & 9.964 & 10.006 & 260 \\
\hline 270 & 10.006 & 10.048 & 10.090 & 10.133 & 10.175 & 10.218 & 10.260 & 10.302 & 10.345 & 10.387 & 10.430 & 270 \\
\hline 280 & 10.430 & 10.472 & 10.515 & 10.558 & 10.600 & 10.643 & 10.685 & 10.728 & 10.771 & 10.814 & 10.856 & 280 \\
\hline 290 & 10.856 & 10.899 & 10.942 & 10.985 & 11.027 & 11.070 & 11.113 & 11.156 & 11.199 & 11.242 & 11.285 & 290 \\
\hline 300 & 11.285 & 11.328 & 11.371 & 11.414 & 11.457 & 11.500 & 11.543 & 11.586 & 11.629 & 11.672 & 11.716 & 300 \\
\hline 310 & 11.716 & 11.759 & 11.802 & 11.845 & 11.888 & 11.932 & 11.975 & 12.018 & 12.062 & 12.105 & 12.148 & 310 \\
\hline 320 & 12.148 & 12.192 & 12.235 & 12.279 & 12.322 & 12.365 & 12.409 & 12.452 & 12.496 & 12.539 & 12.583 & 320 \\
\hline 330 & 12.583 & 12.626 & 12.670 & 12.714 & 12.757 & 12.801 & 12.845 & 12.888 & 12.932 & 12.976 & 13.019 & 330 \\
\hline 340 & 13.019 & 13.063 & 13.107 & 13.150 & 13.194 & 13.238 & 13.282 & 13.326 & 13.370 & 13.413 & 13.457 & 340 \\
\hline 350 & 13.457 & 13.501 & 13.545 & 13.589 & 13.633 & 13.677 & 13.721 & 13.765 & 13.809 & 13.853 & 13.897 & 350 \\
\hline 360 & 13.897 & 13.941 & 13.985 & 14.029 & 14.073 & 14.117 & 14.161 & 14.205 & 14.249 & 14.294 & 14.338 & 360 \\
\hline 370 & 14.338 & 14.382 & 14.426 & 14.470 & 14.514 & 14.559 & 14.603 & 14.647 & 14.691 & 14.736 & 14.780 & 370 \\
\hline 380 & 14.780 & 14.824 & 14.869 & 14.913 & 14.957 & 15.002 & 15.046 & 15.090 & 15.135 & 15.179 & 15.223 & 380 \\
\hline 390 & 15.223 & 15.268 & 15.312 & 15.357 & 15.401 & 15.446 & 15.490 & 15.535 & 15.579 & 15.623 & 15.668 & 390 \\
\hline 400 & 15.668 & 15.713 & 15.757 & 15.802 & 15.846 & 15.891 & 15.935 & 15.980 & 16.024 & 16.069 & 16.114 & 400 \\
\hline 410 & 16.114 & 16.158 & 16.203 & 16.247 & 16.292 & 16.337 & 16.381 & 16.426 & 16.471 & 16.515 & 16.560 & 410 \\
\hline 420 & 16.560 & 16.605 & 16.650 & 16.694 & 16.739 & 16.784 & 16.828 & 16.873 & 16.918 & 16.963 & 17.008 & 420 \\
\hline 430 & 17.008 & 17.052 & 17.097 & 17.142 & 17.187 & 17.232 & 17.276 & 17.321 & 17.366 & 17.411 & 17.456 & 430 \\
\hline 440 & 17.456 & 17.501 & 17.545 & 17.590 & 17.635 & 17.680 & 17.725 & 17.770 & 17.815 & 17.860 & 17.904 & 440 \\
\hline 450 & 17.904 & 17.949 & 17.994 & 18.039 & 18.084 & 18.129 & 18.174 & 18.219 & 18.264 & 18.309 & 18.354 & 450 \\
\hline 460 & 18.354 & 18.399 & 18.444 & 18.489 & 18.534 & 18.579 & 18.624 & 18.669 & 18.714 & 18.759 & 18.804 & 460 \\
\hline 470 & 18.804 & 18.849 & 18.894 & 18.939 & 18.984 & 19.029 & 19.074 & 19.119 & 19.165 & 19.210 & 19.255 & 470 \\
\hline 480 & 19.255 & 19.300 & 19.345 & 19.390 & 19.435 & 19.480 & 19.525 & 19.570 & 19.615 & 19.660 & 19.705 & 480 \\
\hline 490 & 19.705 & 19.750 & 19.795 & 19.841 & 19.886 & 19.931 & 19.976 & 20.021 & 20.066 & 20.111 & 20.156 & 490 \\
\hline 500 & 20.156 & 20.201 & 20.246 & 20.291 & 20.336 & 20.381 & 20.426 & 20.471 & 20.517 & 20.562 & 20.607 & 500 \\
\hline${ }^{\circ} \mathrm{C}$ & 0 & 1 & 2. & 3 & 4 & 5 & 6 & 7 & 8 & 9 & 10 & ${ }^{\circ} \mathrm{C}$ \\
\hline
\end{tabular}


Table 2A. Platinel II, degrees Celsius versus millivolts - Continued

Blectromotive force in absolute millivolts. Temperature in degrees C (Int. 1948). Reference junctions at $0^{\circ} \mathrm{C}$.

\begin{tabular}{|c|c|c|c|c|c|c|c|c|c|c|c|c|}
\hline${ }^{\circ} \mathrm{C}$ & 0 & 1 & 2 & 3 & 4 & 5 & 6 & 7 & 8 & 9 & 10 & ${ }^{\circ} \mathrm{C}$ \\
\hline & \multicolumn{11}{|c|}{ Millivolts } & \multirow[b]{2}{*}{500} \\
\hline 500 & 20.156 & 20.201 & 20.246 & 20.291 & 20.336 & 20.381 & 20.426 & 20.471 & 20.517 & 20.562 & 20.607 & \\
\hline 510 & 20.607 & 20.652 & 20.697 & 20.742 & 20.787 & 20.832 & 20.877 & 20.922 & 20.967 & 21.012 & 21.057 & 510 \\
\hline 520 & 21.057 & 21.102 & 21.148 & 21.193 & 21.238 & 21.283 & 21.328 & 21.373 & 21.418 & 21.463 & 21.508 & 520 \\
\hline 530 & 21.508 & 21.553 & 21.598 & 21.643 & 21.688 & 21.733 & 21.778 & 21.824 & 21.869 & 21.914 & 21.959 & 530 \\
\hline 540 & 21.959 & 22.004 & 22.049 & 22.094 & 22.139 & 22.184 & 22.229 & 22.274 & 22.319 & 22.364 & 22.409 & 540 \\
\hline 550 & 22.409 & 22.454 & 22.500 & 22.545 & 22.590 & 22.635 & 22.680 & 22.725 & 22.770 & 22.815 & 22.860 & 550 \\
\hline 560 & 22.860 & 22.905 & 22.950 & 22.995 & 23.040 & 23.085 & 23.131 & 23.176 & 23.221 & 23.266 & 23.311 & 560 \\
\hline 570 & 23.311 & 23.356 & 23.401 & 23.446 & 23.491 & 23.536 & 23.581 & 23.626 & 23.671 & 23.716 & 23.761 & 570 \\
\hline 580 & 23.761 & 23.807 & 23.852 & 23.897 & 23.942 & 23.987 & 24.032 & 24.077 & 24.122 & 24.167 & 24.212 & 580 \\
\hline 590 & 24.212 & 24.257 & 24.302 & 24.347 & 24.392 & 24.437 & 24.483 & 24.528 & 24.573 & 24.618 & 24.663 & 590 \\
\hline 600 & 24.663 & 24.708 & 24.753 & 24.798 & 24.843 & 24.888 & 24.933 & 24.978 & 25.023 & 25.068 & 25.113 & 600 \\
\hline 610 & 25.113 & 25.159 & 25.204 & 25.249 & 25.294 & 25.339 & 25.384 & 25.429 & 25.474 & 25.519 & 25.564 & 610 \\
\hline 620 & 25.564 & 25.609 & 25.654 & 25.699 & 25.744 & 25.790 & 25.835 & 25.880 & 25.925 & 25.970 & 26.015 & 020 \\
\hline 630 & 26.015 & 26.060 & 26.105 & 26.150 & 26.195 & 26.240 & 26.285 & 26.330 & 26.375 & 26.420 & 26.464 & 630 \\
\hline 640 & 26.464 & 26.509 & 26.554 & 26.598 & 26.643 & 26.688 & 26.732 & 26.777 & 26.821 & 26.866 & 26.911 & 640 \\
\hline 650 & 26.911 & 26.955 & 27.000 & 27.044 & 27.089 & 27.133 & 27.178 & 27.222 & 27.267 & 27.311 & 27.356 & 650 \\
\hline 660 & 27.356 & 27.400 & 27.445 & 27.489 & 27.533 & 27.578 & 27.622 & 27.666 & 27.711 & 27.755 & 27.799 & 660 \\
\hline 670 & 27.799 & 27.844 & 27.888 & 27.932 & 27.977 & 28.021 & 28.065 & 28.109 & 28.154 & 28.198 & 28.242 & 670 \\
\hline 680 & 28.242 & 28.286 & 28.330 & 28.374 & 28.418 & 28.463 & 28.507 & 28.551 & 28.595 & 28.639 & 28.683 & 680 \\
\hline 690 & 28.683 & 28.727 & 28.771 & 28.815 & 28.859 & 28.903 & 28.947 & 28.991 & 29.035 & 29.079 & 29.123 & 690 \\
\hline 700 & 29.123 & 29.166 & 29.210 & 29.254 & 29.298 & 29.342 & 29.386 & 29.429 & 29.473 & 29.517 & 29.561 & 700 \\
\hline 710 & 29.561 & 29.605 & 29.648 & 29.692 & 29.736 & 29.779 & 29.823 & 29.867 & 29.910 & 29.954 & 29.998 & 710 \\
\hline 720 & 29.998 & 30.041 & 30.085 & 30.128 & 30.172 & 30.215 & 30.259 & 30.302 & 30.346 & 30.389 & 30.433 & 720 \\
\hline 730 & 30.433 & 30.476 & 30.520 & 30.563 & 30.607 & 30.650 & 30.693 & 30.737 & 30.780 & 30.823 & 30.867 & 730 \\
\hline 740 & 30.867 & 30.910 & 30.953 & 30.997 & 31.040 & 31.083 & 31.126 & 31.170 & 31.213 & 31.256 & 31.299 & 740 \\
\hline 750 & 31.299 & 31.342 & 31.385 & 31.429 & 31.472 & 31.515 & 31.558 & 31.601 & 31.644 & 31.687 & 31.730 & 750 \\
\hline 760 & 31.730 & 31.773 & 31.816 & 31.859 & 31.902 & 31.945 & 31.988 & 32.031 & 32.074 & 32.116 & 32.159 & 760 \\
\hline 770 & 32.159 & 32.202 & 32.245 & 32.288 & 32.331 & 32.373 & 32.416 & 32.459 & 32.502 & 32.544 & 32.587 & 770 \\
\hline 780 & 32.587 & 32.630 & 32.672 & 32.715 & 32.758 & 32.800 & 32.843 & 32.886 & 32.928 & 32.971 & 33.013 & 780 \\
\hline 790 & 33.013 & 33.056 & 33.098 & 33.141 & 33.183 & 33.226 & 33.268 & 33.311 & 33.353 & 33.395 & 33.438 & 790 \\
\hline 800 & 33.438 & 33.480 & 33.523 & 33.565 & 33.607 & 33.650 & 33.692 & 33.734 & 33.776 & 33.819 & 33.861 & 800 \\
\hline 810 & 33.861 & 33.903 & 33.945 & 33.987 & 34.030 & 34.072 & 34.114 & 34.156 & 34.198 & 34.240 & 34.282 & 810 \\
\hline 820 & 34.282 & 34.324 & 34.366 & 34.408 & 34.450 & 34.492 & 34.534 & 34.576 & 34.618 & 34.660 & 34.702 & 820 \\
\hline 830 & 34.702 & 34.744 & 34.786 & 34.827 & 34.869 & 34.911 & 34.953 & 34.995 & 35.036 & 35.078 & 35.120 & 830 \\
\hline 840 & 35.120 & 35.162 & 35.203 & 35.245 & 35.287 & 35.328 & 35.370 & 35.412 & 35.453 & 35.495 & 35.536 & 840 \\
\hline 850 & 35.536 & 35.578 & 35.619 & 35.661 & 35.702 & 35.744 & 35.785 & 35.827 & 35.868 & 35.910 & 35.951 & 850 \\
\hline 860 & 35.951 & 35.992 & 36.034 & 36.075 & 36.116 & 36.158 & 36.199 & 36.240 & 36.281 & 36.323 & 36.364 & 860 \\
\hline 870 & 36.364 & 36.405 & 36.446 & 36.487 & 36.529 & 36.570 & 36.611 & 36.652 & 36.693 & 36.734 & 36.775 & 870 \\
\hline 880 & 36.775 & 36.816 & 36.857 & 36.898 & 36.939 & 36.980 & 37.021 & 37.062 & 37.103 & 37.144 & 37.185 & 880 \\
\hline 890 & 37.185 & 37.225 & 37.266 & 37.307 & 37.348 & 37.389 & 37.429 & 37.470 & 37.511 & 35.552 & 37.592 & 890 \\
\hline 900 & 37.592 & 37.633 & 37.674 & 37.714 & 37.755 & 37.795 & 37.836 & 37.877 & 37.917 & 37.958 & 37.998 & 900 \\
\hline 910 & 37.998 & 38 & 38.079 & 38.120 & 38.160 & 38.200 & 38.241 & 38.281 & 38.322 & 38.362 & 38.402 & 910 \\
\hline 920 & 38.402 & 38.443 & 38.483 & 38.523 & 38.563 & 38.604 & 38.644 & 38.684 & 38.724 & 38.764 & 38.805 & 920 \\
\hline 930 & 38.805 & 38.845 & 38.885 & 38.925 & 38.965 & 39.005 & 39.045 & 39.085 & 39.125 & 39.165 & 39.205 & 930 \\
\hline 940 & 39.205 & 39.245 & 39.285 & 39.325 & 39.365 & 39.405 & 39.444 & 39.484 & 39.524 & 39.564 & 39.604 & 940 \\
\hline 950 & 39.604 & 39.643 & 39.683 & 39.723 & 39.763 & 39.802 & 39.842 & 39.882 & 39.921 & 39.961 & 40.001 & 950 \\
\hline 960 & 40.001 & 40.040 & 40.080 & 40.119 & 40.159 & 40.198 & 40.238 & 40.277 & 40.317 & 40.356 & 40.395 & 960 \\
\hline 970 & 40.395 & 40.435 & 40.474 & 40.514 & 40.553 & 40.592 & 40.631 & 40.671 & 40.710 & 40.749 & 40.788 & 970 \\
\hline 980 & 40.788 & 40.828 & 40.867 & 40.906 & 40.945 & 40.984 & 41.023 & 41.062 & 41.102 & 41.141 & 41.180 & 980 \\
\hline 990 & 41.180 & 41.219 & 41.258 & 41.297 & 41.336 & 41.374 & 41.413 & 41.452 & 41.491 & 41.530 & 41.569 & 990 \\
\hline 1000 & 41.569 & 41.608 & 41.646 & 41.685 & 41.724 & 41.763 & 41.802 & 41.840 & 41.879 & 41.918 & 41.956 & 1000 \\
\hline 1010 & 41.956 & 41.995 & 42.033 & 42.072 & 42.111 & 42.149 & 88 & & & & 342 & 1010 \\
\hline 1020 & 42.342 & 42.380 & 42.418 & 42.457 & 42.495 & 42.534 & 42.572 & 42.610 & 42.649 & 42.687 & 42.725 & 1020 \\
\hline 1030 & 42.725 & 42.763 & 42.801 & 42.840 & 42.878 & 42.916 & 42.954 & 42.992 & 43.030 & 43.068 & 43.107 & 1030 \\
\hline 1040 & 43.107 & 43.145 & 43.183 & 43.221 & 43.259 & 43.297 & 43.334 & 43. & & 43.448 & 43.486 & 1040 \\
\hline 1050 & 43.486 & 43.524 & 43.562 & 43.600 & 43.637 & 43.675 & 43.713 & 43.751 & 43.788 & 43.826 & 43.864 & 1050 \\
\hline 1060 & 43.864 & 43.901 & 43.939 & 43.976 & 44.014 & 44.052 & 44.089 & 44.127 & 44.164 & 44.202 & 44.239 & 1060 \\
\hline 1070 & 44.239 & 44.277 & 44.314 & 44.351 & 44.389 & 44.426 & 44.464 & 44.501 & 44.538 & 44.575 & 44.613 & 1070 \\
\hline 1080 & 44.613 & 44.650 & 44.687 & 44.724 & 44.762 & 44.799 & 44.836 & 44.873 & 44.910 & 44.947 & 44.984 & 1080 \\
\hline 1090 & 44.984 & 45.021 & 45.058 & 45.095 & 45.132 & 45.169 & 45.206 & 45.243 & 45.280 & 45.317 & 45.354 & 1090 \\
\hline 1100 & 45.354 & 45.391 & 45.427 & 45.464 & 45.501 & 45.538 & 45.574 & 45.611 & 45.648 & 45.685 & 45.721 & 1100 \\
\hline${ }^{\circ} \mathrm{C}$ & 0 & 1 & 2 & 3 & 4 & 5 & 6 & 7 & 8 & 9 & 10 & ${ }^{\circ} \mathrm{C}$ \\
\hline
\end{tabular}


Table 2A. Platinel II, degrees Celsius versus millivolts - Continued

Electromotive force in absolute millivolts. Temperature in degrees C (Int. 1948). Reference functions at $0^{\circ} \mathrm{C}$.

\begin{tabular}{|c|c|c|c|c|c|c|c|c|c|c|c|c|}
\hline${ }^{\circ} \mathrm{C}$ & 0 & 1 & 2 & 3 & 4 & 5 & 6 & 7 & 8 & 9 & 10 & ${ }^{\circ} \mathrm{c}$ \\
\hline & \multicolumn{11}{|c|}{ Millivolts } & \\
\hline 1100 & 45.354 & 45.391 & 45.427 & 45.464 & 45.501 & 45.538 & 45.574 & 45.611 & 45.648 & 45.685 & 45.721 & 1100 \\
\hline 1110 & 45.721 & 45.758 & 45.794 & 45.831 & 45.868 & 45.904 & 45.941 & 45.977 & 46.014 & 46.050 & 46.087 & 1110 \\
\hline 1120 & 46.087 & 46.123 & 46.160 & 46.196 & 46.232 & 46.269 & 46.305 & 46.341 & 46.378 & 46.414 & 46.450 & 1120 \\
\hline 1130 & 46.450 & 46.486 & 46.523 & 46.559 & 46.595 & 46.631 & 46.667 & 46.703 & 46.739 & 46.775 & 46.811 & 1130 \\
\hline 1140 & 46.811 & 46.847 & 46.883 & 46.919 & 46.955 & 46.991 & 47.027 & 47.063 & 47.099 & 47.135 & 47.171 & 1140 \\
\hline 1150 & 47.171 & 47.206 & 47.242 & 47.278 & 47.314 & 47.350 & 47.385 & 47.421 & 47.457 & 47.492 & 47.528 & 1150 \\
\hline 1160 & 47.528 & 47.563 & 47.599 & 47.635 & 47.670 & 47.706 & 47.741 & 47.777 & 47.812 & 47.848 & 47.883 & 1160 \\
\hline 1170 & 47.883 & 47.918 & 47.954 & 47.989 & 48.024 & 48.060 & 48.095 & 48.130 & 48.166 & 48.201 & 48.236 & 1170 \\
\hline 1180 & 48.236 & 48.271 & 48.306 & 48.341 & 48.377 & 48.412 & 48.447 & 48.482 & 48.517 & 48.552 & 48.587 & 1180 \\
\hline 1190 & 48.587 & 48.622 & 48.657 & 48.692 & 48.727 & 48.761 & 48.796 & 48.831 & 48.866 & 48.901 & 48.936 & 1190 \\
\hline 1200 & 48.936 & 48.970 & 49.005 & 49.040 & 49.075 & 49.109 & 49.144 & 49.179 & 49.213 & 49.248 & 49.282 & 1200 \\
\hline 1210 & 49.282 & 49.317 & 49.351 & 39.386 & 49.420 & 49.455 & 49.489 & 49.524 & 49.558 & 49.592 & 49.627 & 1210 \\
\hline 1220 & 49.627 & 49.661 & 49.696 & 49.730 & 49.764 & 49.798 & 49.833 & 49.867 & 49.901 & 49.935 & 49.969 & 1220 \\
\hline 1230 & 49.969 & 50.003 & 50.037 & 50.072 & 50.106 & 50.140 & 50.174 & 50.208 & 50.242 & 50.276 & 50.310 & 1230 \\
\hline 1240 & 50.310 & 50.343 & 50.377 & 50.411 & 50.445 & 50.479 & 50.513 & 50.546 & 50.580 & 50.614 & 50.648 & 1240 \\
\hline 1250 & 50.648 & 50.681 & 50.715 & 50.749 & 50.782 & 50.816 & 50.850 & 50.883 & 50.917 & 50.950 & 50.984 & 1250 \\
\hline 1260 & 50.984 & 51.017 & 51.051 & 51.084 & 51.117 & 51.151 & 51.184 & 51.218 & 51.251 & 51.284 & 51.318 & 1260 \\
\hline 1270 & 51.318 & 51.351 & 51.384 & 51.417 & 51.450 & 51.484 & 51.517 & 51.550 & 51.583 & 51.616 & 51.649 & 1270 \\
\hline 1280 & 51.649 & 51.682 & 51.715 & 51.748 & 51.781 & 51.814 & 51.847 & 51.880 & 51.913 & 51.946 & 51.979 & 1280 \\
\hline 1290 & 51.979 & 52.012 & 52.044 & 52.077 & 52.110 & 52.143 & 52.175 & 52.208 & 52.241 & 52.273 & 52.306 & 1290 \\
\hline 1300 & 52.306 & 52.339 & 52.371 & 52.404 & 52.436 & 52.469 & 52.501 & 52.534 & 52.566 & 52.599 & 52.631 & 1300 \\
\hline 1310 & 52.631 & 52.664 & 52.696 & 52.728 & 52.761 & 52.793 & 52.825 & 52.858 & 52.890 & 52.922 & 52.954 & 1310 \\
\hline 1320 & 52.954 & 52.986 & 53.019 & 53.051 & 53.083 & 53.115 & 53.147 & 53.179 & 53.211 & 53.243 & 53.275 & 1320 \\
\hline 1330 & 53.275 & 53.307 & 53.339 & 53.371 & 53.403 & 53.435 & 53.466 & 53.498 & 53.530 & 53.562 & 53.594 & 1330 \\
\hline 1340 & 53.594 & 53.625 & 53.657 & 53.689 & 53.721 & 53.752 & 53.784 & 53.815 & 53.847 & 53.879 & 53.910 & 1340 \\
\hline 1350 & 53.910 & 53.942 & 53.973 & 54.005 & 54.036 & 54.068 & 54.099 & 54.130 & 54.162 & 54.193 & 54.224 & 1350 \\
\hline 1360 & 54.224 & 54.256 & 54.287 & 54.318 & 54.349 & 54.381 & 54.412 & 54.443 & 54.474 & 54.505 & 54.536 & 1360 \\
\hline 1370 & 54.536 & 54.568 & -- & -- & -- & -- & -- & -- & -- & -- & -- & 1370 \\
\hline • $\mathrm{C}$ & 0 & 1 & 2 & 3 & 4 & 5 & 6 & 7 & 8 & 9 & 10 & ${ }^{\circ} \mathrm{C}$ \\
\hline
\end{tabular}


Table 3A. Platinel II, millivolts versus degrees Fahrenheit

Electromotive force in absolute millivolts. Temperature in degrees $\mathrm{F} . *$ Reference junctions at $32^{\circ} \mathrm{F}$.

\begin{tabular}{|c|c|c|c|c|c|c|c|c|c|c|c|c|}
\hline Millivolts & .000 & .100 & .200 & .300 & .400 & .500 & .600 & .700 & .800 & .900 & 1.000 & Millivolts \\
\hline & \multicolumn{11}{|c|}{ Degrees $\mathrm{F}$} & \multirow{3}{*}{$\begin{array}{l}-2.000 \\
-1.000 \\
-0.000\end{array}$} \\
\hline $\begin{array}{l}-2.000 \\
-1.000\end{array}$ & $\begin{array}{r}-101.9 \\
-31.3\end{array}$ & $\begin{array}{r}-109.6 \\
-38.0\end{array}$ & $\begin{array}{r}-117.3 \\
-44.7\end{array}$ & $\begin{array}{r}-125.2 \\
-51.6\end{array}$ & $\begin{array}{r}-133.2 \\
-58.5\end{array}$ & $\begin{array}{r}-141.4 \\
-65.5\end{array}$ & $\begin{array}{r}-149.7 \\
-72.6\end{array}$ & $\begin{array}{c}-- \\
-79.8\end{array}$ & $\begin{array}{c}-- \\
-87.0\end{array}$ & $\begin{array}{c}-- \\
-94.4\end{array}$ & -101.9 & \\
\hline-0.000 & 32.0 & 25.9 & 19.8 & 13.6 & 7.4 & 1.0 & -5.3 & -11.7 & -18.1 & -24.7 & -31.3 & \\
\hline+0.000 & 32.0 & 38.0 & 44.0 & 49.9 & 55.8 & 61.7 & 67.5 & 73.3 & 79.0 & 84.7 & 90.3 & +0.000 \\
\hline 1.000 & 90.3 & 95.9 & 101.5 & 107.1 & 112.6 & 118.1 & 123.5 & 128.9 & 134.3 & 139.7 & 145.0 & 1.000 \\
\hline 2.000 & 145.0 & 150.3 & 155.6 & 160.9 & 166.1 & 171.3 & 176.5 & 181.7 & 186.8 & 191.9 & 197.0 & 2.000 \\
\hline 3.000 & 197.0 & 202.1 & 207.1 & 212.1 & 217.1 & 222.1 & 227.1 & 232.1 & 237.0 & 241.9 & 246.8 & 3.000 \\
\hline 4.000 & 246.8 & 251.7 & 256.6 & 261.4 & 266.2 & 271.0 & 275.8 & 280.6 & 285.3 & 290.1 & 294.8 & 4.000 \\
\hline 5.000 & 294.8 & 299.5 & 304.2 & 308.9 & 313.6 & 318.3 & 322.9 & 327.6 & 332.2 & 336.8 & 341.4 & 5.000 \\
\hline 6.000 & 341.4 & 346.0 & 350.6 & 355.2 & 359.8 & 364.3 & 368.8 & 373.3 & 377.8 & 382.3 & 386.8 & 6.000 \\
\hline 7.000 & 386.8 & 391.3 & 395.8 & 400.3 & 404.8 & 409.2 & 413.6 & 418.0 & 422.4 & 426.8 & 431.3 & 7.000 \\
\hline 8.000 & 431.3 & 435.7 & 440.0 & 444.4 & 448.8 & 453.2 & 457.5 & 461.9 & 466.2 & 470.5 & 474.9 & 8.000 \\
\hline 9.000 & 474.9 & 479.2 & 483.5 & 487.8 & 492.1 & 496.4 & 500.7 & 505.0 & 509.2 & 513.5 & 517.8 & 9.000 \\
\hline 10.000 & 517.8 & 522.0 & 526.3 & 530.5 & 534.7 & 539.0 & 543.2 & 547.4 & 551.6 & 555.8 & 560.0 & 10.000 \\
\hline 11.000 & 560.0 & 564.2 & 568.4 & 572.6 & 576.8 & 581.0 & 585.2 & 589.4 & 593.5 & 597.7 & 601.8 & 11.000 \\
\hline 12.000 & 601.8 & 606.0 & 610.2 & 614.3 & 618.4 & 622.6 & 626.7 & 630.8 & 635.0 & 639.1 & 643.2 & 12.000 \\
\hline 13.000 & 643.2 & 647.3 & 651.4 & 655.6 & 659.7 & 663.8 & 667.9 & 672.0 & 676.0 & 680.1 & 684.2 & 13.000 \\
\hline 14.000 & 684.2 & 688.3 & 692.4 & 696.5 & 700.5 & 704.6 & 708.7 & 712.8 & 716.8 & 720.9 & 724.9 & 14.000 \\
\hline 15.000 & 724.9 & 729.0 & 733.1 & 737.1 & 741.2 & 745.2 & 749.3 & 753.3 & 757.3 & 761.4 & 765.4 & 15.000 \\
\hline 16.000 & 765.4 & 769.5 & 773.5 & 777.5 & 781.6 & 785.6 & 789.6 & 793.6 & 797.7 & 801.7 & 805.7 & 16.000 \\
\hline 17.000 & 805.7 & 809.7 & 813.7 & 817.8 & 821.8 & 825.8 & 829.8 & 833.8 & 837.8 & 841.8 & 845.8 & 17.000 \\
\hline 18.000 & 845.8 & 849.8 & 853.8 & 857.8 & 861.8 & 865.8 & 869.8 & 873.8 & 877.8 & 881.8 & 885.8 & 18.000 \\
\hline 19.000 & 885.8 & 889.8 & 893.8 & 897.8 & 901.8 & 905.8 & 909.8 & 913.8 & 917.8 & 921.8 & 925.8 & 19.000 \\
\hline 20.000 & 925.8 & 929.8 & 933.8 & 937.8 & 941.7 & 945.7 & 949.7 & 953.7 & 957.7 & 961.7 & 965.7 & 20.000 \\
\hline 21.000 & 965.7 & 969.7 & 973.7 & 977.7 & 981.7 & 985.7 & 989.7 & 993.7 & 997.7 & 1001.7 & 1005.6 & 21.000 \\
\hline 22.000 & 1005.6 & 1009.6 & 1013.6 & 1017.6 & 1021.6 & 1025.6 & 1029.6 & 1033.6 & 1037.6 & 1041.6 & 1045.6 & 22.000 \\
\hline 23.000 & 1045.6 & 1049.6 & 1053.6 & 1057.6 & 1061.6 & 1065.6 & 1069.6 & 1073.5 & 1077.5 & 1081.5 & 1085.5 & 23.000 \\
\hline 24.000 & 1085.5 & 1089.5 & 1093.5 & 1097.5 & 1101.5 & 1105.5 & 1109.5 & 1113.5 & 1117.5 & 1121.5 & 1125.5 & 24.000 \\
\hline 25.000 & 1125.5 & 1129.5 & 1133.5 & 1137.4 & 1141.4 & 1145.4 & 1149.4 & 1153.4 & 1157.4 & 1161.4 & 1165.4 & 25.000 \\
\hline 26.000 & 1165.4 & 1169.4 & 1173.4 & 1177.4 & 1181.4 & 1185.4 & 1189.5 & 1193.5 & 1197.5 & 1201.6 & 1205.6 & 26.000 \\
\hline 27.000 & 1205.6 & 1209.7 & 1213.7 & 1217.7 & 1221.8 & 1225.8 & 1229.9 & 1233.9 & 1238.0 & 1242.1 & 1246.2 & 27.000 \\
\hline 28.000 & 1246.2 & 1250.2 & 1254.3 & 1258.4 & 1262.4 & 1266.5 & 1270.6 & 1274.7 & 1278.8 & 1282.9 & 1287.0 & 28.000 \\
\hline 29.000 & 1287.0 & 1291.1 & 1.295 .2 & 1299.3 & 1303.4 & 1307.4 & 1311.6 & 1315.7 & 1319.9 & 1324.0 & 1328.1 & 29.000 \\
\hline 30.000 & 1328.1 & 1332.4 & 1336.4 & 1340.5 & 1344.6 & 1348.8 & 1352.9 & 1357.1 & 1361.2 & 1365.4 & 1369.5 & 30.000 \\
\hline 31.000 & 1369.5 & 1373.7 & 1377.9 & 1382.0 & 1386.2 & 1390.4 & 1394.6 & 1398.7 & 1402.9 & 1407.1 & 1411.3 & 31.000 \\
\hline 32.000 & 1411.3 & 1415.5 & 1419.7 & 1423.9 & 1428.1 & 1432.3 & 1436.5 & 1440.8 & 1445.0 & 1449.2 & 1453.4 & 32.000 \\
\hline 33.000 & 1453.4 & 1457.7 & 1461.9 & 1466.1 & 1470.4 & 1474.6 & 1478.9 & 1483.1 & 1487.4 & 1491.7 & 1495.9 & 33.000 \\
\hline 34.000 & 1495.9 & 1500.2 & 1504.5 & 1508.8 & 1513.0 & 1517.3 & 1521.6 & 1525.9 & 1530.2 & 1534.5 & 1538.8 & 34.000 \\
\hline 35.000 & 1538.8 & 1543.1 & 1547.5 & 1551.8 & 1556.1 & 1560.4 & 1564.8 & 1569.1 & 1573.4 & 1577.8 & 1582.1 & 35.000 \\
\hline 36.000 & 1582.1 & 1586.5 & 1590.8 & 1595.2 & 1599.6 & 1604.0 & 1608.3 & 1612.7 & 1617.1 & 1621.5 & 1625.9 & 36.000 \\
\hline 37.000 & 1625.9 & 1630.3 & 1634.7 & 1639.1 & 1643.5 & 1647.9 & 1652.3 & 1656.8 & 1661.2 & 1665.6 & 1670.1 & 37.000 \\
\hline 38.000 & 1670.1 & 1674.5 & 1679.0 & 1683.4 & 1687.9 & 1692.4 & 1696.8 & 1701.3 & 1705.8 & 1710.3 & 1714.8 & 38.000 \\
\hline 39.000 & 1714.8 & 1719.3 & 1723.8 & 1728.3 & 1732.8 & 1737.3 & 1741.8 & 1746.4 & 1750.9 & 1755.4 & 1760.0 & 39.000 \\
\hline 40.000 & 1760.0 & 1764.5 & 1769.1 & 1773.6 & 1778.2 & 1782.8 & 1787.4 & 1791.9 & 1796.5 & 1801.1 & 1805.7 & 40.000 \\
\hline 41.000 & 1805.7 & 1810.3 & 1814.9 & 1819.6 & 1824.2 & 1828.8 & 1833.4 & 1838.1 & 1842.7 & 1847.4 & 1852.0 & 41.000 \\
\hline 42.000 & 1852.0 & 1856.7 & 1861.4 & 1866.1 & 1870.7 & 1875.4 & 1880.1 & 1884.8 & 1889.5 & 1894.2 & 1899.0 & 42.000 \\
\hline 43.000 & 1899.0 & 1903.7 & 1908.4 & 1913.2 & 1917.9 & 1922.7 & 1927.4 & 1932.2 & 1937.0 & 1941.7 & 1946.5 & 43.000 \\
\hline 44.000 & 1946.5 & 1951.3 & 1956.1 & 1960.9 & 1565.7 & 1970.6 & 1975.4 & 1980.2 & 1935.1 & 1989.9 & 1954.8 & 44.000 \\
\hline 45.000 & 1994.8 & $199 \% .6$ & 2004.5 & 2009.4 & 2014.3 & 2019.2 & 2024.1 & 2029.0 & 2033.9 & 2038.8 & 2043.7 & 45.000 \\
\hline 46.000 & 2043.7 & 2043.7 & 2053.6 & 2058.6 & 2063.5 & 2068.5 & 2073.5 & 2078.4 & 2083.4 & 2088.4 & 2093.4 & 46.000 \\
\hline 47.000 & 2093.4 & 2098.5 & 2103.5 & 2108.5 & 2113.5 & 2118.6 & 2123.6 & 2128.7 & 2133.8 & 2138.9 & 2144.0 & 47.000 \\
\hline 48.000 & 2144.0 & 2149.1 & 2154.2 & 2159.3 & 2164.4 & 2169.5 & 2174.7 & 2179.8 & 2185.0 & 2190.2 & 2195.3 & 48.000 \\
\hline 49.000 & 2195.3 & 2200.5 & 2205.7 & 2210.9 & 2216.1 & 2221.4 & 2226.6 & 2231.8 & 2237.1 & 2242.3 & 2247.6 & 49.000 \\
\hline 50.000 & 2247.12 & 2252.9 & 2258.2 & 2263.5 & 2268.8 & 2274.1 & 2279.5 & 2284.8 & 2290.1 & 2295.5 & 2300.9 & 50.000 \\
\hline 51.000 & 2300. & 2306.2 & 2311.6 & 2317.1 & 2322.5 & 2327.9 & 2333.3 & 2338.8 & 2344.2 & 2349.7 & 2355.2 & 51.000 \\
\hline 52.000 & $2355 . .2$ & 2360.7 & 2366.2 & 2371.7 & 2377.2 & 2382.7 & 2388.3 & 2393.8 & 2399.4 & 2405.0 & 2410.6 & 52.000 \\
\hline 53.000 & 2410.6 & 2416.2 & 2421.8 & 2427.4 & 2433.0 & 2438.7 & 2444.4 & 2450.0 & 2455.7 & 2461.4 & 2467.1 & 53.000 \\
\hline 54.000 & 2467.1 & 2472.9 & 2478.6 & 2484.4 & 2490.1 & 2495.9 & 2501.6 & -- & -- & -- & -- & 54.000 \\
\hline Millivolts & .000 & .100 & .200 & .300 & .400 & .500 & .600 & .700 & .800 & .900 & 1.000 & Millivolts \\
\hline
\end{tabular}

*Based on the International Practical Temperature Scale of 1948. 
Table 4A. Platinel II, degrees Fahrenheit versus millivolts

Electromotive force in absolute millivolts. Temperature in degrees F.* Reference junctions at $32^{\circ} \mathrm{F}$.

\begin{tabular}{|c|c|c|c|c|c|c|c|c|c|c|c|c|}
\hline$\cdot F$ & 0 & 1 & 2 & 3 & 4 & 5 & 6 & 7 & 8 & 9 & 10 & ${ }^{\circ} \mathrm{F}$ \\
\hline & \multicolumn{11}{|c|}{ Millivolts } & \multirow[b]{2}{*}{-140} \\
\hline-140 & -2.483 & -2.495 & -2.508 & -2.520 & -2.532 & -2.544 & -2.556 & -2.568 & -2.580 & -2.592 & -2.603 & \\
\hline-130 & -2.360 & -2.373 & -2.385 & -2.397 & -2.410 & -2.422 & -2.434 & -2.447 & -2.459 & -2.471 & -2.483 & -130 \\
\hline-120 & -2.234 & -2.247 & -2.260 & -2.272 & -2.285 & -2.298 & -2.310 & -2.323 & -2.335 & -2.348 & -2.360 & -120 \\
\hline-110 & -2.106 & -2.119 & -2.132 & -2.145 & -2.158 & -2.170 & -2.183 & -2.196 & -2.209 & -2.222 & -2.234 & -110 \\
\hline-100 & -1.974 & -1.988 & -2.001 & -2.014 & -2.027 & -2.040 & -2.053 & -2.067 & -2.080 & -2.093 & -2.106 & -100 \\
\hline-90 & -1.840 & -1.854 & -1.867 & -1.881 & -1.894 & -1.908 & -1.921 & -1.934 & -1.948 & -1.961 & -1.974 & -90 \\
\hline-80 & -1.703 & -1.717 & -1.731 & -1.745 & -1.758 & -1.772 & -1.786 & -1.799 & -1.813 & -1.827 & -1.840 & -80 \\
\hline-70 & -1.564 & -1.578 & -1.592 & -1.606 & -1.620 & -1.634 & -1.648 & -1.662 & -1.676 & -1.689 & -1.703 & -70 \\
\hline-60 & -1.422 & -1.436 & -1.450 & -1.465 & -1.479 & -1.493 & -1.507 & -1.522 & -1.536 & -1.550 & -1.564 & -60 \\
\hline-50 & -1.277 & -1.292 & -1.306 & -1.321 & -1.335 & -1.350 & -1.364 & -1.379 & -1.393 & -1.407 & -1.422 & -50 \\
\hline-40 & -1.130 & -1.145 & -1.160 & -1.174 & -1.189 & -1.204 & -1.219 & -1.233 & -1.248 & -1.263 & -1.277 & -40 \\
\hline-30 & -0.980 & -0.996 & -1.011 & -1.026 & -1.041 & -1.056 & -1.071 & -1.085 & -1.100 & -1.115 & -1.130 & -30 \\
\hline-20 & -0.828 & -0.844 & -0.859 & -0.874 & -0.890 & -0.905 & -0.920 & -0.935 & -0.950 & -0.965 & -0.980 & -20 \\
\hline-10 & -0.674 & -0.690 & -0.705 & -0.721 & -0.736 & -0.752 & -0.767 & -0.782 & -0.798 & -0.813 & -0.828 & -10 \\
\hline-0 & -0.517 & -0.533 & -0.549 & -0.565 & -0.580 & -0.596 & -0.612 & -0.627 & -0.643 & -0.658 & -0.674 & -0 \\
\hline+0 & -0.517 & -0.501 & -0.486 & -0.470 & -0.454 & -0.438 & -0.422 & -0.406 & -0.390 & -0.374 & -0.358 & +0 \\
\hline 10 & -0.358 & -0.342 & -0.326 & -0.310 & -0.294 & -0.278 & -0.262 & -0.245 & -0.229 & -0.213 & -0.197 & 10 \\
\hline 20 & -0.197 & -0.180 & -0.164 & -0.148 & -0.131 & -0.115 & -0.099 & -0.082 & -0.066 & -0.049 & -0.033 & 20 \\
\hline 30 & -0.033 & -0.017 & 0.000 & 0.017 & 0.033 & 0.050 & 0.066 & 0.083 & 0.100 & 0.116 & 0.133 & 30 \\
\hline 40 & 0.133 & 0.150 & 0.166 & 0.183 & 0.200 & 0.217 & 0.233 & 0.250 & 0.267 & 0.284 & 0.301 & 40 \\
\hline 50 & 0.301 & 0.318 & 0.335 & 0.352 & 0.369 & 0.386 & 0.403 & 0.420 & 0.437 & 0.454 & 0.471 & 50 \\
\hline 60 & 0.471 & 0.488 & 0.505 & 0.523 & 0.540 & 0.557 & 0.574 & 0.592 & 0.609 & 0.626 & 0.643 & 60 \\
\hline 70 & 0.643 & 0.661 & 0.678 & 0.696 & 0.713 & 0.730 & 0.748 & 0.765 & 0.783 & 0.800 & 0.818 & 70 \\
\hline 80 & 0.818 & 0.835 & 0.853 & 0.871 & 0.888 & 0.906 & 0.923 & 0.941 & 0.959 & 0.977 & 0.994 & 80 \\
\hline 90 & 0.994 & 1.012 & 1.030 & 1.048 & 1.065 & 1.083 & 1.101 & 1.119 & 1.137 & 1.155 & 1.173 & 90 \\
\hline 100 & 1.173 & 1.191 & 1.209 & 1.227 & 1.245 & 1.263 & 1.281 & 1.299 & 1.317 & 1.335 & 1.353 & 100 \\
\hline 110 & 1.353 & 1.371 & 1.389 & 1.408 & 1.426 & 1.444 & 1.462 & 1.481 & 1.499 & 1.517 & 1.535 & 110 \\
\hline 120 & 1.535 & 1.554 & 1.572 & 1.590 & 1.609 & 1.627 & 1.646 & 1.664 & 1.683 & 1.701 & 1.720 & 120 \\
\hline 130 & 1.720 & 1.738 & 1.757 & 1.775 & 1.794 & 1.812 & 1.831 & 1.850 & 1.868 & 1.887 & 1.906 & 130 \\
\hline 140 & 1.906 & 1.924 & 1.943 & 1.962 & 1.981 & 1.999 & 2.018 & 2.037 & 2.056 & 2.075 & 2.094 & 140 \\
\hline 150 & 2.094 & 2.113 & 2.131 & 2.150 & 2.169 & 2.188 & 2.207 & 2.226 & 2.245 & 2.264 & 2.283 & 150 \\
\hline 160 & 2.283 & 2.302 & 2.322 & 2.341 & 2.360 & 2.379 & 2.398 & 2.417 & 2.436 & 2.456 & 2.475 & 160 \\
\hline 170 & 2.475 & 2.494 & 2.513 & 2.533 & 2.552 & 2.571 & 2.591 & 2.610 & 2.629 & 2.649 & 2.668 & 170 \\
\hline 180 & 2.668 & 2.687 & 2.707 & 2.726 & 2.746 & 2.765 & 2.785 & 2.804 & 2.824 & 2.843 & 2.863 & 180 \\
\hline 190 & 2.863 & 2.883 & 2.902 & 2.922 & 2.941 & 2.961 & 2.981 & 3.000 & 3.020 & 3.040 & 3.060 & 190 \\
\hline 200 & 3.060 & 3.079 & 3.099 & 3.119 & 3.139 & 3.158 & 3.178 & 3.198 & 3.218 & 3.238 & 3.258 & 200 \\
\hline 210 & 3.258 & 3.278 & 3.298 & 3.318 & 3.338 & 3.357 & 3.377 & 3.397 & 3.417 & 3.438 & 3.458 & 210 \\
\hline 220 & 3.458 & 3.478 & 3.498 & 3.518 & 3.538 & 3.558 & 3.578 & 3.598 & 3.619 & 3.639 & 3.659 & 220 \\
\hline 230 & 3.659 & 3.679 & 3.699 & 3.720 & 3.740 & 3.760 & 3.781 & 3.801 & 3.821 & 3.842 & 3.862 & 230 \\
\hline 240 & 3.862 & 3.882 & 3.903 & 3.923 & 3.944 & 3.964 & 3.984 & 4.005 & 4.025 & 4.046 & 4.066 & 240 \\
\hline 250 & 4.066 & 4.087 & 4.107 & 4.128 & 4.149 & 4.169 & 4.190 & 4.210 & 4.231 & 4.252 & 4.272 & 250 \\
\hline 260 & 4.272 & 4.293 & 4.314 & 4.334 & 4.355 & 4.376 & 4.397 & 4.417 & 4.438 & 4.459 & 4.480 & 260 \\
\hline 270 & 4.480 & 4.500 & 4.521 & 4.542 & 4.563 & 4.584 & 4.605 & 4.626 & 4.647 & 4.668 & 4.688 & 270 \\
\hline 280 & 4.688 & 4.709 & 4.730 & 4.751 & 4.772 & 4.793 & 4.814 & 4.835 & 4.856 & 4.878 & 4.899 & 280 \\
\hline 290 & 4.899 & 4.920 & 4.941 & 4.962 & 4.983 & 5.004 & 5.025 & -5.047 & 5.068 & 5.089 & 5.110 & 290 \\
\hline 300 & 5.110 & 5.131 & 5.153 & 5.174 & 5.195 & 5.216 & 5.238 & 5.259 & 5.280 & 5.302 & 5.323 & 300 \\
\hline 310 & 5.323 & 5.344 & 5.366 & 5.387 & 5.409 & 5.430 & 5.451 & 5.473 & 5.494 & 5.516 & 5.537 & 310 \\
\hline 320 & 5.537 & 5.559 & 5.580 & 5.602 & 5.623 & 5.645 & 5.666 & 5.688 & 5.709 & 5.731 & 5.753 & 320 \\
\hline 330 & 5.753 & 5.774 & 5.796 & 5.818 & 5.839 & 5.861 & 5.883 & 5.904 & 5.926 & 5.948 & 5.969 & 330 \\
\hline 340 & 5.969 & 5.991 & 6.013 & 6.035 & 6.056 & 6.078 & 6.100 & 6.122 & 6.144 & 6.165 & 6.187 & 340 \\
\hline 350 & 6.187 & 6.209 & 6.231 & 6.253 & 6.275 & 6.297 & 6.319 & 6.341 & 6.363 & 6.384 & 6.406 & 350 \\
\hline 360 & 6.406 & 6.428 & 6.450 & 6.472 & 6.494 & 6.516 & 6.538 & 6.561 & 6.583 & 6.605 & 6.627 & 360 \\
\hline 370 & 6.627 & 6.649 & 6.671 & 6.693 & 6.715 & 6.737 & 6.759 & 6.782 & 6.804 & 6.826 & 6.848 & 370 \\
\hline 380 & 6.848 & 6.870 & 6.893 & 6.915 & 6.937 & 6.959 & 6.982 & 7.004 & 7.026 & 7.048 & 7.071 & 380 \\
\hline 390 & 7.071 & 7.093 & 7.115 & 7.138 & 7.160 & 7.182 & 7.205 & 7.227 & 7.249 & 7.272 & 7.294 & 390 \\
\hline 400 & 7.294 & 7.317 & 7.339 & 7.362 & 7.384 & 7.406 & 7.429 & 7.451 & 7.474 & 7.496 & 7.519 & 400 \\
\hline${ }^{\circ} \mathrm{F}$ & 0 & 1 & 2 & 3 & 4 & 5 & 6 & 7 & 8 & 9 & 10 & ${ }^{\circ} \mathrm{F}$ \\
\hline
\end{tabular}

*Based on the International Practical Temperature Scale of 1948. 
Table 4A. Platinel II, degrees Fahrenheit versus millivolts - Continued

Electromotive force in absolute millivolts. Temperature in degrees $\mathrm{F} . *$ Reference junctions at $32^{\circ} \mathrm{F}$,

\begin{tabular}{|c|c|c|c|c|c|c|c|c|c|c|c|c|}
\hline${ }^{\circ} \mathrm{F}$ & 0 & 1 & 2 & 3 & 4 & 5 & 6 & 7 & 8 & 9 & 10 & ${ }^{\circ} \mathrm{F}$ \\
\hline & \multicolumn{11}{|c|}{ Millivolts } & \multirow[b]{2}{*}{400} \\
\hline 400 & 7.294 & 7.317 & 7.339 & 7.362 & 7.384 & 7.406 & 7.429 & 7.451 & 7.474 & 7.496 & 7.519 & \\
\hline 410 & 7.519 & 7.541 & 7.564 & 7.587 & 7.609 & 7.632 & 7.654 & 7.677 & 7.699 & 7.722 & 7.745 & 410 \\
\hline 420 & 7.745 & 7.767 & 7.790 & 7.813 & 7.835 & 7.858 & 7.881 & 7.903 & 7.926 & 7.949 & 7.971 & 420 \\
\hline 430 & 7.971 & 7.994 & 8.017 & 8.040 & 8.062 & 8.085 & 8.108 & 8.131 & 8.153 & 8.176 & 8.199 & 430 \\
\hline 440 & 8.199 & 8.222 & 8.245 & 8.268 & 8.290 & 8.313 & 8.336 & 8.359 & 8.382 & 8.405 & 8.428 & 440 \\
\hline 450 & 8.428 & 8.451 & 8.473 & 8.496 & 8.519 & 8.542 & 8.565 & 8.588 & 8.611 & 8.634 & 8.657 & 450 \\
\hline 460 & 8.657 & 8.680 & 8.703 & 8.726 & 8.749 & 8.772 & 8.795 & 8.818 & 8.842 & 8.865 & 8.888 & 460 \\
\hline 470 & 8.888 & 8.911 & 8.934 & 8.957 & 8.980 & 9.003 & 9.026 & 9.050 & 9.073 & 9.096 & 9.119 & 470 \\
\hline 480 & 9.119 & 9.142 & 9.165 & 9.189 & 9.212 & 9.235 & 9.258 & 9.282 & 9.305 & 9.328 & 9.351 & 480 \\
\hline 490 & 9.351 & 9.375 & 9.398 & 9.421 & 9.444 & 9.468 & 9.491 & 9.514 & 9.538 & 9.561 & 9.584 & 490 \\
\hline 500 & 9.584 & 9.608 & 9.631 & 9.654 & 9.678 & 9.701 & 9.725 & 9.748 & 9.771 & 9.795 & 9.818 & 500 \\
\hline 510 & 9.818 & 9.842 & 9.865 & 9.889 & 9.912 & 9.935 & 9.959 & 9.982 & 10.006 & 10.029 & 10.053 & 510 \\
\hline 520 & 10.053 & 10.076 & 10.100 & 10.123 & 10.147 & 10.170 & 10.194 & 10.218 & 10.241 & 10.265 & 10.288 & 520 \\
\hline 530 & 10.288 & 10.312 & 10.335 & 10.359 & 10.383 & 10.406 & 10.430 & 10.454 & 10.477 & 10.501 & 10.524 & 530 \\
\hline 540 & 10.524 & 10.548 & 10.572 & 10.595 & 10.619 & 10.643 & 10.666 & 10.690 & 10.714 & 10.738 & 10.761 & 540 \\
\hline 550 & 10.761 & 10.785 & 10.809 & 10.833 & 10.856 & 10.880 & 10.904 & 10.928 & 10.951 & 10.975 & 10.999 & 550 \\
\hline 560 & 10.999 & 11.023 & 11.046 & 11.070 & 11.094 & 11.118 & 11.142 & 11.166 & 11.189 & 11.213 & 11.237 & 560 \\
\hline 570 & 11.237 & 11.261 & 11.285 & 11.309 & 11.333 & 11.357 & 11.380 & 11.404 & 11.428 & 11.452 & 11.476 & 570 \\
\hline 580 & 11.476 & 11.500 & 11.524 & 11.548 & 11.572 & 11.596 & 11.620 & 11.644 & 11.668 & 11.692 & 11.716 & 580 \\
\hline 590 & 11.716 & 11.740 & 11.764 & 11.788 & 11.812 & 11.836 & 11.860 & 11.884 & 11.908 & 11.932 & 11.956 & 590 \\
\hline 600 & 11.956 & 11.980 & 12.004 & 12.028 & 12.052 & 12.076 & 12.100 & 12.124 & 12.148 & 12.172 & 12.197 & 600 \\
\hline 610 & 12.197 & 12.221 & 12.245 & 12.269 & 12.293 & 12.317 & 12.341 & 12.365 & 12.390 & 12.414 & 12.438 & 610 \\
\hline 620 & 12.438 & 12.462 & 12.486 & 12.510 & 12.535 & 12.559 & 12.583 & 12.607 & 12.631 & 12.656 & 12.680 & 620 \\
\hline 630 & 12.680 & 12.704 & 12.728 & 12.752 & 12.777 & 12.801 & 12.825 & 12.849 & 12.874 & 12.898 & 12.922 & 630 \\
\hline 640 & 12.922 & 12.946 & 12.971 & 12.995 & 13.019 & 13.044 & 13.068 & 13.092 & 13.116 & 13.141 & 13.165 & 640 \\
\hline 650 & 13.165 & 13.189 & 13.214 & 13.238 & 13.262 & 13.287 & 13.311 & 13.335 & 13.360 & 13.384 & 13.408 & 650 \\
\hline 660 & 13.408 & 13.433 & 13.457 & 13.482 & 13.506 & 13.530 & 13.555 & 13.579 & 13.604 & 13.628 & 13.652 & 660 \\
\hline 670 & 13.652 & 13.677 & 13.701 & 13.726 & 13.750 & 13.775 & 13.799 & 13.823 & 13.848 & 13.872 & 13.897 & 670 \\
\hline 680 & 13.897 & 13.921 & 13.946 & 13.970 & 13.995 & 14.019 & 14.044 & 14.068 & 14.093 & 14.117 & 14.142 & 680 \\
\hline 690 & 14.142 & 14.166 & 14.191 & 14.215 & 14.240 & 14.264 & 14.289 & 14.313 & 14.338 & 14.362 & 14.387 & 690 \\
\hline 700 & 14.387 & 14.411 & 14.436 & 14.460 & 14.485 & 14.510 & 14.534 & 14.559 & 14.583 & 14.608 & 14.632 & 700 \\
\hline 710 & 14.632 & 14.657 & 14.682 & 14.706 & 14.731 & 14.755 & 14.780 & 14.805 & 14.829 & 14.854 & 14.878 & 710 \\
\hline 720 & 14.878 & 14.903 & 14.928 & 14.952 & 14.977 & 15.002 & 15.026 & 15.051 & 15.075 & 15.100 & 15.125 & 720 \\
\hline 730 & 15.125 & 15.149 & 15.174 & 15.199 & 15.223 & 15.248 & 15.273 & 15.297 & 15.322 & 15.347 & 15.371 & 730 \\
\hline 740 & 15.371 & 15.396 & 15.421 & 15.446 & 15.470 & 15.495 & 15.520 & 15.544 & 15.569 & 15.594 & 15.619 & 740 \\
\hline 750 & 15.619 & 15.643 & 15.668 & 15.693 & 15.717 & 15.742 & 15.767 & 15.792 & 15.816 & 15.841 & 15.866 & 750 \\
\hline 760 & 15.866 & 15.891 & 15.915 & 15.940 & 15.965 & 15.990 & 16.014 & 16.039 & 16.064 & 16.089 & 16.114 & 760 \\
\hline 770 & 16.114 & 16.138 & 16.163 & 16.188 & 16.213 & 16.238 & 16.262 & 16.287 & 16.312 & 16.337 & 16.362 & 770 \\
\hline 780 & 16.362 & 16.386 & 16.411 & 16.436 & 16.461 & 16.486 & 16.510 & 16.535 & 16.560 & 16.585 & 16.610 & 780 \\
\hline 790 & 16.610 & 16.635 & 16.659 & 16.684 & 16.709 & 16.734 & 16.759 & 16.784 & 16.809 & 16.833 & 16.858 & 790 \\
\hline 800 & 16.858 & 16.883 & 16.908 & 16.933 & 16.958 & 16.983 & 17.008 & 17.032 & 17.057 & 17.082 & 17.107 & 800 \\
\hline 810 & 17.107 & 17.132 & 17.157 & 17.182 & 17.207 & 17.232 & 17.256 & 17.281 & 17.306 & 17.331 & 17.356 & 810 \\
\hline 820 & 17.356 & 17.381 & 17.406 & 17.431 & 17.456 & 17.481 & 17.506 & 17.530 & 17.555 & 17.580 & 17.605 & 820 \\
\hline 830 & 17.605 & 17.630 & 17.655 & 17.680 & 17.705 & 17.730 & 17.755 & 17.780 & 17.805 & 17.830 & 17.855 & 830 \\
\hline 840 & 17.855 & 17.880 & 17.904 & 17.929 & 17.954 & 17.979 & 18.004 & 18.029 & 18.054 & 18.079 & 18.104 & 840 \\
\hline 850 & 18.104 & 18.129 & 18.154 & 18.179 & 18.204 & 18.229 & 18.254 & 18.279 & 18.304 & 18.329 & 18.354 & 850 \\
\hline 860 & 18.354 & 18.379 & 18.404 & 18.429 & 18.454 & 18.479 & 18.504 & 18.529 & 18.554 & 18.579 & 18.604 & 860 \\
\hline 870 & 18.604 & 18.629 & 18.654 & 18.679 & 18.704 & 18.729 & 18.754 & 18.779 & 18.804 & 18.829 & 18.854 & 870 \\
\hline 880 & 18.854 & 18.879 & 18.904 & 18.929 & 18.954 & 18.979 & 19.004 & 19.029 & 19.054 & 19.079 & 19.104 & 880 \\
\hline 890 & 19.104 & 19.129 & 19.155 & 19.180 & 19.205 & 19.230 & 19.255 & 19.280 & 19.305 & 19.330 & 19.355 & 890 \\
\hline 900 & 19.355 & 19.380 & 19.405 & 19.430 & 19.455 & 19.480 & 19.505 & 19.530 & 19.555 & 19.580 & 19.605 & 900 \\
\hline 910 & 19.605 & 19.630 & 19.655 & 19.680 & 19.705 & 19.730 & 19.755 & 19.780 & 19.805 & 19.831 & 19.856 & 910 \\
\hline 920 & 19.856 & 19.881 & 19.906 & 19.931 & 19.956 & 19.981 & 20.006 & 20.031 & 20.056 & 20.081 & 20.106 & 920 \\
\hline 930 & 20.106 & 20.131 & 20.156 & 20.181 & 20.206 & 20.231 & 20.256 & 20.281 & 20.306 & 20.331 & 20.356 & 930 \\
\hline 940 & 20.356 & 20.381 & 20.406 & 20.431 & 20.456 & 20.482 & 20.507 & 20.532 & 20.557 & 20.582 & 20.607 & 940 \\
\hline 950 & 20.607 & 20.632 & 20.657 & 20.682 & 20.707 & 20.732 & 20.757 & 20.782 & 20.807 & 20.832 & 20.857 & 950 \\
\hline 960 & 20.857 & 20.882 & 20.907 & 20.932 & 20.957 & 20.982 & 21.007 & 21.032 & 21.057 & 21.082 & 21.107 & 960 \\
\hline 970 & 21.107 & 21.132 & 21.158 & 21.183 & 21.208 & 21.233 & 21.258 & 21.283 & 21.308 & 21.333 & 21.358 & 970 \\
\hline 980 & 21.358 & 21.383 & 21.408 & 21.433 & 21.458 & 21.483 & 21.508 & 21.533 & 21.558 & 21.583 & 21.608 & 980 \\
\hline 990 & 21.608 & 21.633 & 21.658 & 21.683 & 21.708 & 21.733 & 21.758 & 21.783 & 21.809 & 21.834 & 21.859 & 990 \\
\hline 1000 & 21.859 & 21.884 & 21.909 & 21.934 & 21.959 & 21.984 & 22.009 & 22.034 & 22.059 & 22.084 & 22.109 & 1000 \\
\hline${ }^{\circ} \mathrm{F}$ & 0 & 1 & 2 & 3 & 4 & 5 & 6 & 7 & 8 & 9 & 10 & ${ }^{\bullet} \mathrm{F}$ \\
\hline
\end{tabular}

*Based on the International Practical Temperature Scale of 1948. 
Table 4A. Platinel II, degrees Fahrenheit versus millivolts - Continued

Electromotive force in absolute millivolts. Temperature in degrees $\mathrm{F} .{ }^{*}$ Reference junctions at $32^{\circ} \mathrm{F}$.

\begin{tabular}{|c|c|c|c|c|c|c|c|c|c|c|c|c|}
\hline${ }^{\circ} \mathrm{F}$ & 0 & 1 & 2 & 3 & 4 & 5 & 6 & 7 & 8 & 9 & 10 & ${ }^{\circ} \mathrm{F}$ \\
\hline & \multicolumn{11}{|c|}{ Millivolts } & \\
\hline 1000 & 21.859 & 21.884 & 21.909 & 21.934 & 21.959 & 21.984 & 22.009 & 22.034 & 22.059 & 22.084 & 22.109 & 1000 \\
\hline 1010 & 22.109 & 22.134 & 22.159 & 22.184 & 22.209 & 22.234 & 22.259 & 22.284 & 22.309 & 22.334 & 22.359 & 1010 \\
\hline 1020 & 22.359 & 22.384 & 22.409 & 22.434 & 22.459 & 22.485 & 22.510 & 22.535 & 22.560 & 22.585 & 22.610 & 1020 \\
\hline 1030 & 22.610 & 22.635 & 22.660 & 22.685 & 22.710 & 22.735 & 22.760 & 22.785 & 22.810 & 22.835 & 22.860 & 1030 \\
\hline 1040 & 22.860 & 22.885 & 22.910 & 22.935 & 22.960 & 22.985 & 23.010 & 23.035 & 23.060 & 23.085 & 23.110 & 1040 \\
\hline 1050 & 23.110 & 23.136 & 23.161 & 23.186 & 23.211 & 23.236 & 23.261 & 23.286 & 23.311 & 23.336 & 23.361 & 1050 \\
\hline 1060 & 23.361 & 23.386 & 23.411 & 23.436 & 23.461 & 23.486 & 23.511 & 23.536 & 23.561 & 23.586 & 23.611 & 1060 \\
\hline 1070 & 23.611 & 23.636 & 23.661 & 23.686 & 23.711 & 23.736 & 23.761 & 23.786 & 23.812 & 23.837 & 23.862 & 1070 \\
\hline 1080 & 23.862 & 23.887 & 23.912 & 23.937 & 23.962 & 23.987 & 24.012 & 24.037 & 24.062 & 24.087 & 24.112 & 1080 \\
\hline 1090 & 24.112 & 24.137 & 24.162 & 24.187 & 24.212 & 24.237 & 24.262 & 24.287 & 24.312 & 24.337 & 24.362 & 1090 \\
\hline 1100 & 24.362 & 24.387 & 24.412 & 24.437 & 24.463 & 24.488 & 24.513 & 24.538 & 24.563 & 24.588 & 24.613 & 1100 \\
\hline 1110 & 24.613 & 24.638 & 24.663 & 24.688 & 24.713 & 24.738 & 24.763 & 24.788 & 24.813 & 24.838 & 24.863 & 1110 \\
\hline 1120 & 24.863 & 24.888 & 24.913 & 24.938 & 24.963 & 24.988 & 25.013 & 25.038 & 25.063 & 25.088 & 25.113 & 1120 \\
\hline 1130 & 25.113 & 25.139 & 25.164 & 25.189 & 25.214 & 25.239 & 25.264 & 25.289 & 25.314 & 25.339 & 25.364 & 1130 \\
\hline 1140 & 25.364 & 25.389 & 25.414 & 25.439 & 25.464 & 25.489 & 25.514 & 25.539 & 25.564 & 25.589 & 25.614 & 1140 \\
\hline 1150 & 25.614 & 25.639 & 25.664 & 25.689 & 25.714 & 25.739 & 25.764 & 25.790 & 25.815 & 25.840 & 25.865 & 1150 \\
\hline 1160 & 25.865 & 25.890 & 25.915 & 25.940 & 25.965 & 25.990 & 26.015 & 26.040 & 26.065 & 26.090 & 26.115 & 1160 \\
\hline 1170 & 26.115 & 26.140 & 26.165 & 26.190 & 26.215 & 26.240 & 26.265 & 26.290 & 26.315 & 26.340 & 26.365 & 1170 \\
\hline 1180 & 26.365 & 26.390 & 26.415 & 26.439 & 26.464 & 26.489 & 26.514 & 26.539 & 26.564 & 26.588 & 26.613 & 1180 \\
\hline 1190 & 26.613 & 26.638 & 26.663 & 26.688 & 26.712 & 26.737 & 26.762 & 26.787 & 26.812 & 26.836 & 26.861 & 1190 \\
\hline 1200 & 26.861 & 26.886 & 26.911 & 26.935 & 26.960 & 26.985 & 27.010 & 27.034 & 27.059 & 27.084 & 27.109 & 1200 \\
\hline 1210 & 27.109 & 27.133 & 27.158 & 27.183 & 27.207 & 27.232 & 27.257 & 27.282 & 27.306 & 27.331 & 27.356 & 1210 \\
\hline 1220 & 27.356 & 27.380 & 27.405 & 27.430 & 27.454 & 27.479 & 27.504 & 27.528 & 27.553 & 27.578 & 27.602 & 1220 \\
\hline 1230 & 27.602 & 27.627 & 27.652 & 27.676 & 27.701 & 27.726 & 27.750 & 27.775 & 27.799 & 27.824 & 27.849 & 1230 \\
\hline 1240 & 27.849 & 27.873 & 27.898 & 27.923 & 27.947 & 27.972 & 27.996 & 28.021 & 28.045 & 28.070 & 28.095 & 1240 \\
\hline 1250 & 28.095 & 28.119 & 28.144 & 28.168 & 28.193 & 28.217 & 28.242 & 28.266 & 28.291 & 28.315 & 28.340 & 1250 \\
\hline 1260 & 28.340 & 28.365 & 28.389 & 28.414 & 28.438 & 28.463 & 28.487 & 28.512 & 28.536 & 28.561 & 28.585 & 1260 \\
\hline 1270 & 28.585 & 28.610 & 28.634 & 28.658 & 28.683 & 28.707 & 28.732 & 28.756 & 28.781 & 28.805 & 28.830 & 1270 \\
\hline 1280 & 28.830 & 28.854 & 28.878 & 28.903 & 28.927 & 28.952 & 28.976 & 29.001 & 29.025 & 29.049 & 29.074 & 1280 \\
\hline 1290 & 29.074 & 29.098 & 29.123 & 29.147 & 29.171 & 29.196 & 29.220 & 29.244 & 29.269 & 29.293 & 29.318 & 1290 \\
\hline 1300 & 29.318 & 29.342 & 29.366 & 29.391 & 29.415 & 29.439 & 29.464 & 29.488 & 29.512 & 29.536 & 29.561 & 1300 \\
\hline 1310 & 29.561 & 29.585 & 29.609 & 29.634 & 29.658 & 29.682 & 29.707 & 29.731 & 29.755 & 29.779 & 29.804 & 1310 \\
\hline 1320 & 29.804 & 29.828 & 29.852 & 29.876 & 29.901 & 29.925 & 29.949 & 29.973 & 29.998 & 30.022 & 30.046 & 1320 \\
\hline 1330 & 30.046 & 30.070 & 30.094 & 30.119 & 30.143 & 30.167 & 30.191 & 30.215 & 30.240 & 30.264 & 30.288 & 1330 \\
\hline 1340 & 30.288 & 30.312 & 30.336 & 30.360 & 30.385 & 30.409 & 30.433 & 30.457 & 30.481 & 30.505 & 30.529 & 1340 \\
\hline 1350 & 30.529 & 30.554 & 30.578 & 30.602 & 30.626 & 30.650 & 30.674 & 30.698 & 30.722 & 30.746 & 30.771 & 1350 \\
\hline 1360 & 30.771 & 30.795 & 30.819 & 30.843 & 30.867 & 30.891 & 30.915 & 30.939 & 30.963 & 30.987 & 31.011 & 1360 \\
\hline 1370 & 31.011 & 31.035 & 31.059 & 31.083 & 31.107 & 31.131 & 31.155 & 31.179 & 31.203 & 31.227 & 31.251 & 1370 \\
\hline 1380 & 31.251 & 31.275 & 31.299 & 31.323 & 31.347 & 31.371 & 31.395 & 31.419 & 31.443 & 31.467 & 31.491 & 1380 \\
\hline 1390 & 31.491 & 31.515 & 31.539 & 31.563 & 31.587 & 31.610 & 31.634 & 31.658 & 31.682 & 31.706 & 31.730 & 1390 \\
\hline 1400 & 31.730 & 31.754 & 31.778 & 31.802 & 31.826 & 31.849 & 31.873 & 31.897 & 31.921 & 31.945 & 31.969 & 1400 \\
\hline 1410 & 31.969 & 31.993 & 32.016 & 32.040 & 32.064 & 32.088 & 32.112 & 32.136 & 32.159 & 32.183 & 32.207 & 1410 \\
\hline 1420 & 32.207 & 32.231 & 32.255 & 32.278 & 32.302 & 32.326 & 32.350 & 32.373 & 32.397 & 32.421 & 32.445 & 1420 \\
\hline 1430 & 32.445 & 32.468 & 32.492 & 32.516 & 32.540 & 32.563 & 32.587 & 32.611 & 32.635 & 32.658 & 32.682 & 1430 \\
\hline 1440 & 32.682 & 32.706 & 32.729 & 32.753 & 32.777 & 32.800 & 32.824 & 32.848 & 32.871 & 32.895 & 32.919 & 1440 \\
\hline 1450 & 32.919 & 32.942 & 32.966 & 32.990 & 33.013 & 33.037 & 33.061 & 33.084 & 33.108 & 33.131 & 33.155 & 1450 \\
\hline 1460 & 33.155 & 33.179 & 33.202 & 33.226 & 33.249 & 33.273 & 33.297 & 33.320 & 33.344 & 33.367 & 33.391 & 1460 \\
\hline 1470 & 33.391 & 33.414 & 33.438 & 33.461 & 33.485 & 33.508 & 33.532 & 33.556 & 33.579 & 33.603 & 33.626 & 1470 \\
\hline 1480 & 33.626 & 33.650 & 33.673 & 33.697 & 33.720 & 33.743 & 33.767 & 33.790 & 33.814 & 33.837 & 33.861 & 1480 \\
\hline 1490 & 33.861 & 33.884 & 33.908 & 33.931 & 33.955 & 33.978 & 34.001 & 34.025 & 34.048 & 34.072 & 34.095 & 1490 \\
\hline 1500 & 34.095 & 34.119 & 34.142 & 34.165 & 34.189 & 34.212 & 34.235 & 34.259 & 34.282 & 34.306 & 34.329 & 1500 \\
\hline 1510 & 34.329 & 34.352 & 34.376 & 34.399 & 34.422 & 34.446 & 34.469 & 34.492 & 34.516 & 34.539 & 34.562 & 1510 \\
\hline 1520 & 34.562 & 34.585 & 34.609 & 34.632 & 34.655 & 34.679 & 34.702 & 34.725 & 34.748 & 34.772 & 34.795 & 1520 \\
\hline 1530 & 34.795 & 34.818 & 34.841 & 34.865 & 34.888 & 34.911 & 34.934 & 34.958 & 34.981 & 35.004 & 35.027 & 1530 \\
\hline 1540 & 35.027 & 35.050 & 35.074 & 35.097 & 35.120 & 35.143 & 35.166 & 35.189 & 35.213 & 35.236 & 35.259 & 1540 \\
\hline 1550 & 35.259 & 35.282 & 35.305 & 35.328 & 35.351 & 35.375 & 35.398 & 35.421 & 35.444 & 35.467 & 35.490 & 1550 \\
\hline 1560 & 35.490 & 35.513 & 35.536 & 35.559 & 35.582 & 35.606 & 35.629 & 35.652 & 35.675 & 35.698 & 35.721 & 1560 \\
\hline 1570 & 35.721 & 35.744 & 35.767 & 35.790 & 35.813 & 35.836 & 35.859 & 35.882 & 35.905 & 35.928 & 35.951 & 1570 \\
\hline 1580 & 35.951 & 35.974 & 35.997 & 36.020 & 36.043 & 36.066 & 36.089 & 36.112 & 36.135 & 36.158 & 36.181 & 1580 \\
\hline 1590 & 36.181 & 36.203 & 36.226 & 36.249 & 36.272 & 36.295 & 36.318 & 36.341 & 36.364 & 36.387 & 36.410 & 1590 \\
\hline 1600 & 36.410 & 36.433 & 36.455 & 36.478 & 36.501 & 36.524 & 36.547 & 36.570 & 36.593 & 36.615 & 36.638 & 1600 \\
\hline$\bullet F$ & 0 & 1 & 2 & 3 & 4 & 5 & 6 & 7 & 8 & 9 & 10 & ${ }^{\circ} \mathrm{F}$ \\
\hline
\end{tabular}

*Based on the International Practical Temperature Scale of 1948. 
Table 4A. Platinel II, degrees Fahrenheit versus millivolts - Continued

Electromotive force in absolute millivolts. Temperature in degrees F.* Reference junctions at $32^{\circ} \mathrm{F}$.

\begin{tabular}{|c|c|c|c|c|c|c|c|c|c|c|c|c|}
\hline${ }^{\bullet} \mathrm{F}$ & 0 & 1 & 2 & 3 & 4 & 5 & 6 & 7 & 8 & 9 & 10 & ${ }^{\circ} \mathrm{F}$ \\
\hline & \multicolumn{11}{|c|}{ Millivolts } & \multirow[b]{2}{*}{1600} \\
\hline 1600 & 36.410 & 36.433 & 36.455 & 36.478 & 36.501 & 36.524 & 36.547 & 36.570 & 36.593 & 36.615 & 36.638 & \\
\hline 1610 & 36.638 & 36.661 & 36.684 & 36.707 & 36.729 & 36.752 & 36.775 & 36.798 & 36.821 & 36.843 & 36.866 & 1610 \\
\hline 1620 & 36.866 & 36.889 & 36.912 & 36.935 & 36.957 & 36.980 & 37.003 & 37.026 & 37.048 & 37.071 & 37.094 & 1620 \\
\hline 1630 & 37.094 & 37.116 & 37.139 & 37.162 & 37.185 & 37.207 & 37.230 & 37.253 & 37.275 & 37.298 & 37.321 & 1630 \\
\hline 1640 & 37.321 & 37.343 & 37.366 & 37.389 & 37.411 & 37.434 & 37.457 & 37.479 & 37.502 & 37.524 & 37.547 & 1640 \\
\hline 1650 & 37.547 & 37.570 & 37.592 & 37.615 & 37.637 & 37.660 & 37.683 & 37.705 & 37.728 & 37.750 & 37.773 & 1650 \\
\hline 1660 & 37.773 & 37.795 & 37.818 & 37.841 & 37.863 & 37.886 & 37.908 & 37.931 & 37.953 & 37.976 & 37.998 & 1660 \\
\hline 1670 & 37.998 & 38.021 & 38.043 & 38.066 & 38.088 & 38.111 & 38.133 & 33.156 & 38.178 & 38.200 & 38.223 & 1670 \\
\hline 1680 & 38.223 & 38.245 & 38.268 & 38.290 & 38.313 & 38.335 & 38.357 & 38.380 & 38.402 & 38.425 & 38.447 & 1680 \\
\hline 1690 & 38.447 & 38.469 & 38.492 & 38.514 & 38.537 & 38.559 & 38.581 & 38.604 & 38.626 & 38.648 & 38.671 & 1690 \\
\hline 1700 & 38.671 & 38.693 & 38.715 & 38.738 & 38.760 & 38.782 & 38.805 & 38.827 & 38.849 & 38.871 & 38.894 & 1700 \\
\hline 1710 & 38.894 & 38.916 & 38.938 & 38.961 & 38.983 & 39.005 & 39.027 & 39.050 & 39.072 & 39.094 & 39.116 & 1710 \\
\hline 1720 & 39.116 & 39.138 & 39.161 & 39.183 & 39.205 & 39.227 & 39.249 & 39.272 & 39.294 & 39.316 & 39.338 & 1720 \\
\hline 1730 & 39.338 & 39.360 & 39.382 & 39.405 & 39.427 & 39.449 & 39.471 & 39.493 & 39.515 & 39.537 & 39.560 & 1730 \\
\hline 1740 & 39.560 & 39.582 & 39.604 & 39.626 & 39.648 & 39.670 & 39.692 & 39.714 & 39.736 & 39.758 & 39.780 & 1740 \\
\hline 1750 & 39.780 & 39.802 & 39.824 & 39.846 & 39.868 & 39.890 & 39.912 & 39.935 & 39.957 & 39.979 & 40.001 & 1750 \\
\hline 1760 & 40.001 & 40.022 & 40.044 & 40.066 & 40.088 & 40.110 & 40.132 & 40.154 & 40.176 & 40.198 & 40.220 & 1760 \\
\hline 1770 & 40.220 & 40.242 & 40.264 & 40.286 & 40.308 & 40.330 & 40.352 & 40.374 & 40.395 & 40.417 & 40.439 & 1770 \\
\hline 1780 & 40.439 & 40.461 & 40.483 & 40.505 & 40.527 & 40.549 & 40.570 & 40.592 & 40.614 & 40.636 & 40.658 & 1780 \\
\hline 1790 & 40.658 & 40.679 & 40.701 & 40.723 & 40.745 & 40.767 & 40.788 & 40.810 & 40.832 & 40.854 & 40.876 & 1790 \\
\hline 1800 & 40.876 & 40.897 & 40.919 & 40.941 & 40.963 & 40.984 & 41.006 & 41.028 & 41.049 & 41.071 & 41.093 & 1800 \\
\hline 1810 & 41.093 & 41.115 & 41.136 & 41.158 & 41.180 & 41.201 & 41.223 & 41.245 & 41.266 & 41.288 & 41.310 & 1810 \\
\hline 1820 & 41.310 & 41.331 & 41.353 & 41.374 & 41.396 & 41.418 & 41.439 & 41.461 & 41.483 & 41.504 & 41.526 & 1820 \\
\hline 1830 & 41.526 & 41.547 & 41.569 & 41.590 & 41.612 & 41.634 & 41.655 & 41.677 & 41.698 & 41.720 & 41.741 & 1830 \\
\hline 1840 & 41.741 & 41.763 & 41.784 & 41.806 & 41.827 & 41.849 & 41.870 & 41.892 & 41.913 & 41.935 & 41.956 & 1840 \\
\hline 1850 & 41.956 & 41.978 & 41.999 & 42.021 & 42.042 & 42.063 & 42.085 & 42.106 & 42.128 & 42.149 & 42.171 & 1850 \\
\hline 1860 & 42.171 & 42.192 & 42.213 & 42.235 & 42.256 & 42.277 & 42.299 & 42.320 & 42.342 & 42.363 & 42.384 & 1860 \\
\hline 1870 & 42.384 & 42.406 & 42.427 & 42.448 & 42.470 & 42.491 & 42.512 & 42.534 & 42.555 & 42.576 & 42.597 & 1870 \\
\hline 1880 & 42.597 & 42.619 & 42.640 & 42.661 & 42.683 & 42.704 & 42.725 & 42.746 & 42.768 & 42.789 & 42.810 & 1880 \\
\hline 1890 & 42.810 & 42.831 & 42.852 & 42.874 & 42.895 & 42.916 & 42.937 & 42.958 & 42.980 & 43.001 & 43.022 & 1890 \\
\hline 1900 & 43.022 & 43.043 & 43.064 & 43.085 & 43.107 & 43.128 & 43.149 & 43.170 & 43.191 & 43.212 & 43.233 & 1900 \\
\hline 1910 & 43.233 & 43.254 & 43.275 & 43.297 & 43.318 & 43.339 & 43.360 & 43.381 & 43.402 & 43.423 & 43.444 & 1910 \\
\hline 1920 & 43.444 & 43.465 & 43.486 & 43.507 & 43.528 & 43.549 & 43.570 & 43.591 & 43.612 & 43.633 & 43.654 & 1920 \\
\hline 1930 & 43.654 & 43.675 & 43.696 & 43.717 & 43.738 & 43.759 & 43.780 & 43.801 & 43.822 & 43.843 & 43.864 & 1930 \\
\hline 1940 & 43.864 & 43.885 & 43.905 & 43.926 & 43.947 & 43.968 & 43.989 & 44.010 & 44.031 & 44.052 & 44.072 & 1940 \\
\hline 1950 & 44.072 & 44.093 & 44.114 & 44.135 & 44.156 & 44.177 & 44.198 & 44.218 & 44.239 & 44.260 & 44.281 & 1950 \\
\hline 1960 & 44.281 & 44.302 & 44.322 & 44.343 & 44.364 & 44.385 & 44.405 & 44.426 & 44.447 & 44.468 & 44.488 & 1960 \\
\hline 1970 & 44.488 & 44.509 & 44.530 & 44.551 & 44.571 & 44.592 & 44.613 & 44.633 & 44.654 & 44.675 & 44.695 & 1970 \\
\hline 1980 & 44.695 & 44.716 & 44.737 & 44.757 & 44.778 & 44.799 & 44.819 & 44.840 & 44.861 & 44.881 & 44.902 & 1980 \\
\hline 1990 & 44.902 & 44.922 & 44.943 & 44.964 & 44.984 & 45.005 & 45.025 & 45.046 & 45.067 & 45.087 & 45.108 & 1990 \\
\hline 2000 & 45.108 & 45.128 & 45.149 & 45.169 & 45.190 & 45.210 & 45.231 & 45.251 & 45.272 & 45.292 & 45.313 & 2000 \\
\hline 2010 & 45.313 & 45.333 & 45.354 & 45.374 & 45.395 & 45.415 & 45.436 & 45.456 & 45.476 & 45.497 & 45.517 & 2010 \\
\hline 2020 & 45.517 & 45.538 & 45.558 & 45.579 & 45.599 & 45.619 & 45.640 & 60 & 45.681 & 45.701 & 45.721 & 2020 \\
\hline 2030 & 45.721 & 45.742 & 45.762 & 45.782 & 45.803 & 45.823 & 45.843 & 45.864 & 45.884 & 45.904 & 45.925 & 2030 \\
\hline 2040 & 45.925 & 45.945 & 45.965 & 45.985 & 46.006 & 46.026 & 46.046 & 46.066 & 46.087 & 46.107 & 46.127 & 2040 \\
\hline 2050 & 46.127 & 46.147 & 46.168 & 46.188 & 46.208 & 46.228 & 46.248 & 46.269 & 46.289 & 46.309 & 46.329 & 2050 \\
\hline 2060 & 46.329 & 46.349 & 46.369 & 46.390 & 46.410 & 46.430 & 46.450 & 46.470 & 46.490 & 46.510 & 46.531 & 2060 \\
\hline 2070 & 46.531 & 46.551 & 46.571 & 46.591 & 46.611 & 46.631 & 46.651 & 46.671 & 46.691 & 46.711 & 46.731 & 2070 \\
\hline 2080 & 46.731 & 46.751 & 46.771 & 46.791 & 46.811 & 46.831 & 46.851 & 46.871 & 46.891 & 46.911 & 46.931 & 2080 \\
\hline 2090 & 46.931 & 46.951 & 46.971 & 46.991 & 47.011 & 47.031 & 47.051 & 47.071 & 47.091 & 47.111 & 47.131 & 2090 \\
\hline 2100 & 47.131 & 47.151 & 47.171 & 47.191 & 47.210 & 47.230 & 47.250 & 47.270 & 47.290 & 47.310 & 47.330 & 2100 \\
\hline 2110 & 47.330 & 47.350 & 47.369 & 47.389 & 47.409 & 47.429 & 47.449 & 47.468 & 47.488 & 47.508 & 47.528 & 2110 \\
\hline 2120 & 47.528 & 47.548 & 47.567 & 47.587 & 47.607 & 47.627 & 47.646 & 47.666 & 47.686 & 47.706 & 47.725 & 2120 \\
\hline 2130. & 47.725 & 47.745 & 47.765 & 47.785 & 47.804 & 47.824 & 47.844 & 47.863 & 47.883 & 47.903 & 47.922 & 2130 \\
\hline 2140 & 47.922 & 47.942 & 47.962 & 47.981 & 48.001 & 48.020 & 48.040 & 48.060 & 48.079 & 48.099 & 48.119 & 2140 \\
\hline 2150 & 48.119 & 48.138 & 48.158 & 48.177 & 48.197 & 48.216 & 48.236 & 48.255 & 48.275 & 48.295 & 48.314 & 2150 \\
\hline 2160 & 48.314 & 48.334 & 48.353 & 48.373 & 48.392 & 48.412 & 48.431 & 48.451 & 48.470 & 48.490 & 48.509 & 2160 \\
\hline 2170 & 48.509 & 48.529 & 48.548 & 48.567 & 48.587 & 48.606 & 48.626 & 48.645 & 48.665 & 48.684 & 48.703 & 2170 \\
\hline 2180 & 48.703 & 38.723 & 48.742 & 48.761 & 48.781 & 48.800 & 48.820 & 48.839 & 48.858 & 48.878 & 48.897 & 2180 \\
\hline 2190 & 48.897 & 48.916 & 48.936 & 48.955 & 48.974 & 48.994 & 49.013 & 49.032 & 49.051 & 49.071 & 49.090 & 2190 \\
\hline 2200 & 49.090 & 49.109 & 49.128 & 49.148 & 49.167 & 49.186 & 49.205 & 49.225 & 49.244 & 49.263 & 49.282 & 2200 \\
\hline${ }^{\circ} \mathrm{F}$ & 0 & 1 & 2 & 3 & 4 & 5 & 6 & 7 & 8 & 9 & 10 & ${ }^{\circ} \mathrm{F}$ \\
\hline
\end{tabular}

*Based on the International Practical Temperature Scale of 1948 
Table 4A. Platinel II, degrees Fahrenheit versus millivolts - Continued

Electromotive force in absolute millivolts. Temperature in degrees $\mathrm{F} . \star$ Reference junctions at $32^{\circ} \mathrm{F}$.

\begin{tabular}{|c|c|c|c|c|c|c|c|c|c|c|c|c|}
\hline$\bullet \mathrm{F}$ & 0 & 1 & 2 & 3 & 4 & 5 & 6 & 7 & 8 & 9 & 10 & ${ }^{\bullet} \mathrm{F}$ \\
\hline & \multicolumn{11}{|c|}{ Millivolts } & \\
\hline 2200 & 49.090 & 49.109 & 49.128 & 49.148 & 49.167 & 49.186 & 49.205 & 49.225 & 49.244 & 49.263 & 49.282 & 2200 \\
\hline 2210 & 49.282 & 49.301 & 49.321 & 49.340 & 49.359 & 49.378 & 49.397 & 49.417 & 49.436 & 49.455 & 49.474 & 2210 \\
\hline 2220 & 49.474 & 49.493 & 49.512 & 49.531 & 49.550 & 49.570 & 49.589 & 49.608 & 49.627 & 49.646 & 49.665 & 2220 \\
\hline 2230 & 49.665 & 49.684 & 49.703 & 49.722 & 49.741 & 49.760 & 49.779 & 49.798 & 49.817 & 49.836 & 49.855 & 2230 \\
\hline 2240 & 49.855 & 49.874 & 49.893 & 49.912 & 49.931 & 49.950 & 49.969 & 49.988 & 50.007 & 50.026 & 50.045 & 2240 \\
\hline 2250 & 50.045 & 50.064 & 50.083 & 50.102 & 50.121 & 50.140 & 50.159 & 50.177 & 50.196 & 50.215 & 50.234 & 2250 \\
\hline 2260 & 50.234 & 50.253 & 50.272 & 50.291 & 50.310 & 50.328 & 50.347 & 50.366 & 50.385 & 50.404 & 50.423 & 2260 \\
\hline 2270 & 50.423 & 50.441 & 50.460 & 50.479 & 50.498 & 50.516 & 50.535 & 50.554 & 50.573 & 50.591 & 50.610 & 2270 \\
\hline 2280 & 50.610 & 50.629 & 50.648 & 50.666 & 50.685 & 50.704 & 50.723 & 50.741 & 50.760 & 50.779 & 50.797 & 2280 \\
\hline 2290 & 50.797 & 50.816 & 50.835 & 50.853 & 50.872 & 50.891 & 50.909 & 50.928 & 50.946 & 50.965 & 50.984 & 2290 \\
\hline 2300 & 50.984 & 51.002 & 51.021 & 51.039 & 51.058 & 51.077 & 51.095 & 51.114 & 51.132 & 51.151 & 51.169 & 2300 \\
\hline 2310 & 51.169 & 51.188 & 51.206 & 51.225 & 51.244 & 51.262 & 51.281 & 51.299 & 51.318 & 51.336 & 51.354 & 2310 \\
\hline 2320 & 51.354 & 51.373 & 51.391 & 51.410 & 51.428 & 51.447 & 51.465 & 51.484 & 51.502 & 51.520 & 51.539 & 2320 \\
\hline 2330 & 51.539 & 51.557 & 51.576 & 51.594 & 51.612 & 51.631 & 51.649 & 51.668 & 51.686 & 51.704 & 51.723 & 2330 \\
\hline 2340 & 51.723 & 51.741 & 51.759 & 51.778 & 51.796 & 51.814 & 51.833 & 51.851 & 51.869 & 51.887 & 51.906 & 2340 \\
\hline 2350 & 51.906 & 51.924 & 51.942 & 51.960 & 51.979 & 51.997 & 52.015 & 52.033 & 52.052 & 52.070 & 52.088 & 2350 \\
\hline 2360 & 52.088 & 52.106 & 52.124 & 52.143 & 52.161 & 52.179 & 52.197 & 52.215 & 52.234 & 52.252 & 52.270 & 2360 \\
\hline 2370 & 52.270 & 52.288 & 52.306 & 52.324 & 52.342 & 52.360 & 52.379 & 52.397 & 52.415 & 52.433 & 52.451 & 2370 \\
\hline 2380 & 52.451 & 52.469 & 52.487 & 52.505 & 52.523 & 52.541 & 52.559 & 52.577 & 52.595 & 52.613 & 52.631 & 2380 \\
\hline 2390 & 52.631 & 52.649 & 52.667 & 52.685 & 52.703 & 52.721 & 52.739 & 52.757 & 52.775 & 52.793 & 52.811 & 2390 \\
\hline 2400 & 52.811 & 52.829 & 52.847 & 52.865 & 52.883 & 52.901 & 52.918 & 52.936 & 52.954 & 52.972 & 52.990 & 2400 \\
\hline 2410 & 52.990 & 53.008 & 53.026 & 53.044 & 53.061 & 53.079 & 53.097 & 53.115 & 53.133 & 53.151 & 53.168 & 2410 \\
\hline 2420 & 53.168 & 53.186 & 53.204 & 53.222 & 53.240 & 53.257 & 53.275 & 53.293 & 53.311 & 53.328 & 53.346 & 2420 \\
\hline 2430 & 53.346 & 53.364 & 53.381 & 53.399 & 53.417 & 53.435 & 53.452 & 53.470 & 53.488 & 53.505 & 53.523 & 2430 \\
\hline 2440 & 53.523 & 53.541 & 53.558 & 53.576 & 53.594 & 53.611 & 53.629 & 53.647 & 53.664 & 53.682 & 53.699 & 2440 \\
\hline 2450 & 53.699 & 53.717 & 53.735 & 53.752 & 53.770 & 53.787 & 53.805 & 53.822 & 53.840 & 53.858 & 53.875 & 2450 \\
\hline 2460 & 53.875 & 53.893 & 53.910 & 53.928 & 53.945 & 53.963 & 53.980 & 53.998 & 54.015 & 54.033 & 54.050 & 2460 \\
\hline 2470 & 54.050 & 54.068 & 54.085 & 54.102 & 54.120 & 54.137 & 54.155 & 54.172 & 54.190 & 54.207 & 54.224 & 2470 \\
\hline 2480 & 54.224 & 54.242 & 54.259 & 54.277 & 54.294 & 54.311 & 54.329 & 54.346 & 54.363 & 54.381 & 54.398 & 2480 \\
\hline 2490 & 54.398 & 54.415 & 54.433 & 54.450 & 54.467 & 54.485 & 54.502 & 54.519 & 54.536 & 54.554 & 54.571 & 2490 \\
\hline 2500 & 54.571 & -- & -- & -- & -- & -- & -- & -- & -- & -- & -- & 2500 \\
\hline${ }^{\circ} \mathrm{F}$ & 0 & 1 & 2 & 3 & 4 & 5 & 6 & 7 & 8 & 9 & 10 & ${ }^{\circ} \mathrm{F}$ \\
\hline
\end{tabular}

*Based on the International Practical Temperature Scale of 1948.

Table 5A. Thermal emf relations between 1813, 1503, Pt 27, and copper

\begin{tabular}{|c|c|c|c|c|c|c|}
\hline \multirow{3}{*}{$\begin{array}{c}\text { Temperature } \\
{ }^{\circ} \mathrm{F} \\
\end{array}$} & \multicolumn{2}{|r|}{1813} & 1503 & Copper & \multirow{2}{*}{$\begin{array}{l}\text { Copper } \\
\text { vs } 1813\end{array}$} & \multirow{2}{*}{$\begin{array}{l}\text { Copper } \\
\text { vs } 1503\end{array}$} \\
\hline & Platinel II & vs Pt 27 & vs Pt 27 & vs Pt 27 & & \\
\hline & \multicolumn{6}{|c|}{ Millivolts } \\
\hline 32 & 0.000 & 0.000 & 0.000 & 0.000 & 0.000 & 0.000 \\
\hline 50 & .301 & .001 & -.300 & .062 & .061 & .362 \\
\hline 75 & .730 & .004 & -.726 & .153 & .149 & .879 \\
\hline 100 & 1.173 & .010 & -1.163 & .250 & .240 & 1.413 \\
\hline 125 & 1.627 & .019 & -1.608 & .354 & .335 & 1.962 \\
\hline 150 & 2.094 & .030 & -2.064 & .464 & .434 & 2.528 \\
\hline 175 & 2.571 & .044 & -2.527 & .580 & .536 & 3.107 \\
\hline 200 & 3.060 & .059 & -3.001 & .703 & .644 & 3.704 \\
\hline 225 & 3.558 & .076 & -3.482 & .831 & .755 & 4.313 \\
\hline 250 & 4.066 & .095 & -3.971 & .966 & .871 & 4.937 \\
\hline 275 & 4.584 & .115 & -4.469 & 1.107 & .992 & 5.576 \\
\hline 300 & 5.110 & .136 & -4.974 & 1.254 & 1.118 & 6.228 \\
\hline 325 & 5.645 & .159 & -5.486 & 1.404 & 1.245 & 6.890 \\
\hline 350 & 6.187 & .182 & -6.005 & 1.560 & 1.378 & 7.565 \\
\hline 375 & 6.737 & .206 & -6.531 & 1.720 & 1.514 & 8.251 \\
\hline 400 & 7.294 & .231 & -7.063 & 1.886 & 1.655 & 8.949 \\
\hline 425 & 7.858 & .256 & -7.602 & 2.055 & 1.799 & 9.657 \\
\hline 450 & 8.428 & .281 & -8.147 & 2.229 & 1.948 & 10.376 \\
\hline 475 & 9.003 & .306 & -8.697 & 2.408 & 2.102 & 11.105 \\
\hline 500 & 9.584 & .331 & -9.253 & 2.591 & 2.260 & 11.844 \\
\hline
\end{tabular}

